\title{
Nonlocal Inadvertent Weather Modification Associated with Wind Farms in the Central United States
}

\author{
Matthew J. Lauridsen (iD) and Brian C. Ancell \\ Texas Tech University, Lubbock, TX, USA \\ Correspondence should be addressed to Matthew J. Lauridsen; matthew.j.lauridsen@gmail.com
}

Received 14 March 2018; Accepted 19 June 2018; Published 6 August 2018

Academic Editor: Anthony R. Lupo

Copyright (c) 2018 Matthew J. Lauridsen and Brian C. Ancell. This is an open access article distributed under the Creative Commons Attribution License, which permits unrestricted use, distribution, and reproduction in any medium, provided the original work is properly cited.

Local effects of inadvertent weather changes within and near wind farms have been well documented by a number of modeling studies and observational campaigns; however, the broader nonlocal atmospheric effects of wind farms are much less clear. The goal of this study is to determine whether wind farm-induced perturbations are able to evolve over periods of days, and over areas of thousands of square kilometers, to modify specific atmospheric features that have large impacts on society and the environment, specifically midlatitude and tropical cyclones. Here, an ensemble modeling approach is utilized with a wind farm parameterization to quantify the sensitivity of meteorological variables to the presence of wind farms. The results show that perturbations to nonlocal midlatitude cyclones caused by a wind farm are statistically significant, with magnitudes of roughly $1 \mathrm{hPa}$ for mean sealevel pressure, $4 \mathrm{~m} / \mathrm{s}$ for surface wind speed, and $15 \mathrm{~mm}$ for maximum 30-minute accumulated precipitation. Cyclone perturbation magnitude is also found to be dependent on wind farm size and location relative to the midlatitude cyclone genesis region and track.

\section{Introduction}

Amid growing emphasis on domestic, renewable, and environmentally friendly energy sources, several renewable energy industries have experienced large growth in the United States and across the globe. One such prominent industry expanding in the Central United States is wind power. To produce power, wind turbines extract kinetic energy from the mean flow, which produces drag on the mean wind and also enhances turbulent kinetic energy (TKE) downwind of the turbine. In turn, an important potential result of the creation of wind farms is the inadvertent modification of weather. Local modification of the atmospheric state near wind farms has been well documented by a number of observational campaigns and modeling studies. Observations show surface temperature is increased at night $[1,2]$ and hub-height wind speed is decreased within and immediately downstream of wind farms [3]. Modeling studies have concluded a decrease of wind speed at hub height [4-9] but a wind speed increase at the surface due to momentum transfer in enhanced vertical mixing $[4,7]$. Surface water vapor mixing ratio has been shown to decrease due to this vertical mixing [4] since the surface is the source of moisture. Additionally, potential temperature has been found to increase under stable atmospheric conditions and at times decrease when the boundary layer is unstable $[4,8-12]$.

In terms of how local atmospheric modifications may evolve, many studies suggest that relatively small perturbations can grow rapidly to modify the atmosphere nonlocally, potentially with regard to high-impact weather events. Lorenz [13] first reported on the fundamental nature underlying such perturbation growth, a phenomenon known as chaos. In recent studies more relevant to the full atmospheric state, Zhang et al. [14] showed that smaller initial condition perturbations grew faster, in both magnitude and spatial size, than larger perturbations introduced to 36-hour forecasts with the MM5 mesoscale model. Other studies have explored high-impact weather features such as tropical cyclones $[15,16]$ and midlatitude cyclones [17-20] 
that exhibit a large sensitivity to initial conditions. Highly sensitive regions involved with tropical cyclone evolution are found to be collocated with the flow toward the cyclone at upper levels [15], and these maxima in sensitivity can occur as far as $4000 \mathrm{~km}$ from the cyclone [16], often to the northwest of the storm. Midlatitude cyclogenesis can be triggered by initial perturbations as shown by an adjoint model [19], and midlatitude cyclones have been shown to be sensitive to low-level temperature advection $[17,18,20]$, specifically during cyclogenesis. Additionally, low-level moisture [17] and upper-level potential vorticity [20] perturbations to the initial state are shown to have a large impact on developing midlatitude cyclones.

Since wind farms have been shown to directly modify the local atmospheric state and large sensitivity of high-impact weather features to the lower atmosphere has been demonstrated, it is reasonable to expect wind farm-induced perturbations may evolve rapidly downstream to affect the weather in a significant way. However, the broader nonlocal atmospheric effects of wind farms on timescales of days are much less clear than those within and surrounding wind farms. Therefore, there is a need to establish whether wind farms are capable of producing modifications to the atmosphere on large temporal and spatial scales which is the goal of this study. This research goal is particularly aimed at addressing the knowledge gap with regard to nonlocal inadvertent weather modification pointed out by the American Meteorological Society, which stated that anthropogenic forcing which can be derived from wind farms could "modify atmospheric circulation and weather patterns on all scales, including synoptic storm tracks, in ways that are just beginning to be explored" [21].

In this study, we examine the sensitivity of midlatitude and tropical cyclones to wind farm-induced perturbations, as these events can significantly affect weather over large areas over periods of days. The key tool we use here to investigate the potential link between wind farms and the nonlocal atmospheric state is the Weather Research and Forecasting (WRF) mesoscale model with a wind farm parameterization introduced in [7]. Rather than assessing wind farm effects on forecast skill, we aim to fundamentally understand the sensitivity of the atmosphere to wind farm effects on the timescale of hours to days. While an adjoint approach [22] is one way to examine the sensitivity of wind farms to nonlocal weather features, it is limited by computational cost and nonlinearity over the simulation window of our experiments (96 hours). Thus, here we use an ensemble-like approach, designed to incorporate wind farm size and location variability, to determine the relationship between nonlocal midlatitude and tropical cyclones to wind farms. The experimental setup is described in the next section. The results are then presented in Section 3. A summary and conclusions of results are provided in Section 4.

\section{Methodology}

Here, we use the Weather Research and ForecastingAdvanced Research WRF (WRF-ARW) mesoscale model version 3.5.1 [23] and simulate wind farms using the wind farm parameterization outlined in [7]. The single domain utilized is $5500 \mathrm{~km}$ by $3700 \mathrm{~km}$ as shown in Figure 1, with a horizontal grid spacing of $10 \mathrm{~km}$ and 40 vertical levels. Wind turbines being simulated in the model are based off of the Siemens SWT-2.3-108 turbine. The turbines have a hub height of $100 \mathrm{~m}$, a rotor diameter of $108 \mathrm{~m}$, cut-in and cutout speeds of 3.0 and $25.0 \mathrm{~ms}^{-1}$, respectively, a power output of $2.3 \mathrm{MW}$, and a standing thrust coefficient of 0.158 . The Fitch scheme to parameterize a wind farm is run under the idealized configuration, with the turbines being placed equidistant from each other in a grid pattern, and the generic thrust and power coefficient curves that are approximate to an actual wind turbine are used. In each horizontal grid cell that makes up the wind farm, there are 324 wind turbines. This equates to a turbine spacing of $5555 / 9 \mathrm{~m}$, or rotor diameter of $5.14 \mathrm{~m}$. GFS data are used for initialization and lateral boundary conditions, which are updated every 6 hours, and the time step is 60 seconds. With the resolution used here $(10 \mathrm{~km})$, this ends up being about a $3: 1$ dynamical downscaling ratio.

Other parameterizations used here include the Thompson scheme [24] for microphysics, the rapid radiative transfer model scheme [25] for longwave radiation and Dudhia scheme [26] for shortwave radiation with 30 minutes between radiation physics calls, the Monin-Obukhov (Janjic) Eta similarity scheme [27] for surface-layer physics, the unified Noah land-surface model [28] for land-surface physics, the Mellor-Yamada-Nakanishi-Niino (MYNN) 2.5-level TKE scheme [29, 30] for boundary-layer physics, and the Kain-Fritsch scheme [31] for cumulus physics with 5 minutes between cumulus physics calls. It should be noted that the wind farm parameterization is only functional when used in conjunction with the MYNN 2.5-level TKE scheme, and this boundary-layer physics parameterization was chosen by the wind farm parameterization developers due to its more reliable prediction of TKE. The TKE calculation by the MYNN 2.5-level TKE scheme is tuned to match results from large eddy simulation (LES).

Ten total cases of midlatitude cyclogenesis (six cases) and tropical cyclogenesis (four cases) are included in this study (listed in Table 1). The model is initialized at $00 \mathrm{Z}$ about 24 hours before cyclone formation for the cases of midlatitude cyclogenesis in an attempt to capture any interaction between the wind farm perturbations and the localized sensitivity field associated with the cyclones demonstrated through prior studies. While it is possible that sensitivity would be different within a natural state that included the wind farm configurations in this study, we assume such differences would be small enough with regard to the climatology of the storm track such that our experiments still reveal valid results regarding short-term cyclone evolution. For the tropical cyclogenesis cases, the 96-hour forecast is initialized at $00 \mathrm{Z}$ when the cyclone was already within the model domain but before the cyclone strengthened. All midlatitude cyclones in this study form along the Rocky Mountains, deepen, and propagate east or northeast across the Central United States. Two of the four tropical cyclones originate in the Gulf of Mexico and make landfall along the 




Figure 1: Members, numbered, of the wind farm location ensemble (in outlined boxes).

TABLE 1: Cases used in the study, the type of cyclone observed in model simulation, and the location ensemble with the largest perturbation.

\begin{tabular}{|c|c|c|}
\hline Cases & $\begin{array}{l}\text { Type of } \\
\text { cyclone }\end{array}$ & Member \\
\hline $\begin{array}{l}24 \text { August } 201100 Z-28 \text { August } \\
201100 Z\end{array}$ & Tropical & 4 \\
\hline $\begin{array}{l}26 \text { August } 2012 \text { 00Z-30 August } \\
201200 Z\end{array}$ & Tropical & 1 \\
\hline 28 May 2013 00Z-1 June 2013 00Z & Midlatitude & 4 \\
\hline $\begin{array}{l}3 \text { October } 2013 \text { 00Z-7 October } \\
201300 Z\end{array}$ & Tropical & 8 \\
\hline $\begin{array}{l}10 \text { October } 2013 \text { 00Z-14 October } \\
201300 Z\end{array}$ & Midlatitude & 6 \\
\hline $\begin{array}{l}13 \text { October } 2013 \text { 00Z-17 October } \\
2013 \text { 00Z }\end{array}$ & Midlatitude & 1 \\
\hline 26 April 2014 00Z-30 April 2014 00Z & Midlatitude & 9 \\
\hline 6 May 2014 00Z-10 May 2014 00Z & Midlatitude & 6 \\
\hline 1 July 2014 00Z-5 July 2014 00Z & Tropical & 4 \\
\hline $\begin{array}{l}12 \text { October } 2014 \text { 00Z-16 October } \\
201400 \mathrm{Z}\end{array}$ & Midlatitude & 4 \\
\hline
\end{tabular}

Gulf Coast of the United States, while the other two are located in the Atlantic Ocean and follow a path that tracks just offshore of the southeastern United States. In turn, unlike the midlatitude cyclones that track much closer to the prescribed wind farms, the tropical cyclones examined here must take advantage of perturbations that have evolved over long distances if they are to be modified.

Predetermined ensembles of wind farm locations and sizes are utilized for each case. First, an ensemble of fixed locations is run for each case, consisting of 10 wind farm locations in the Central United States as seen in Figure 1. The wind farms in this ensemble of locations are $300 \mathrm{~km}$ by $300 \mathrm{~km}$, or $90,000 \mathrm{~km}^{2}$. While this wind farm size is very large, the purpose of this location ensemble is to capture the most sensitive areas with regard to the evolution of the cyclones, providing an appropriate place to execute an ensemble of wind farm sizes. The member of the ensemble that produces the most significant changes to the midlatitude cyclone or tropical cyclone is then chosen as the location to run the fixed ensemble of wind farm sizes. To determine which wind farm location produces the largest perturbations, a control run is utilized in which the wind farm parameterization is turned off. The members of the location ensemble are then differenced with the control run (location member minus control; examples are shown in Figures 2 and 3), and the location that produces the largest perturbations to minimum cyclone pressure and maximum cyclone 10-meter wind speed is then selected as the location for the size ensemble. Wind farm sizes included in the size ensemble are shown in Figure 4, which in this example are located over region 6 . Some members in the wind farm size ensemble are much larger than wind farms in operation today. However, they are included in the ensemble to have an estimation of how large wind farms must be to produce a significant change to nonlocal meteorology. Additionally, wind farms larger than current wind farms can be seen as an aggregation of many wind farms in the same region.

After an initial examination of results, it was determined that some perturbations (found by differencing the wind farm run with the control run) are not directly created by the wind farm in the model but are possibly created by the spurious propagation of noise that can then evolve throughout the forecast. These "unrealistic" perturbations occur in regions where convective precipitation and nonconvective precipitation are occurring, possibly due in part to the Boolean response of the convection parameterization as described in [14, 32, 33]. However, turning off the cumulus parameterization with a finer grid spacing was ineffective in removing the unrealistic noise here. Both studies [34] and [35] found evidence of these unrealistic processes 


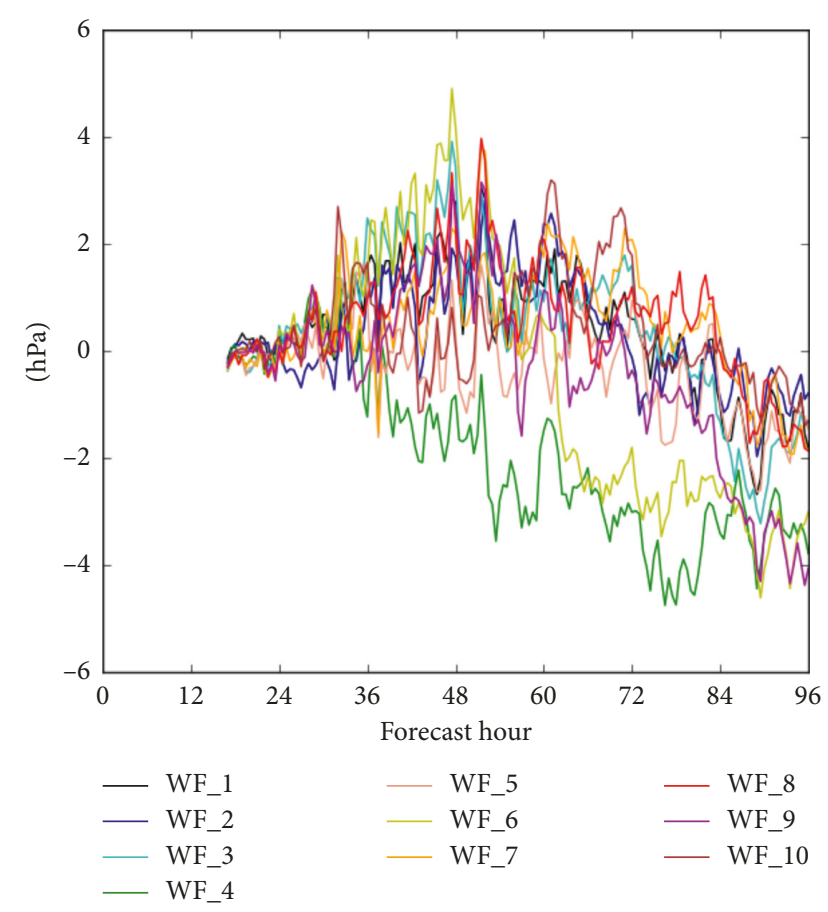

FIgURE 2: Example time series of cyclone minimum sea-level pressure perturbation from the control run. The case shown here represents the tropical cyclone case initialized on 24 August 2011 00Z.

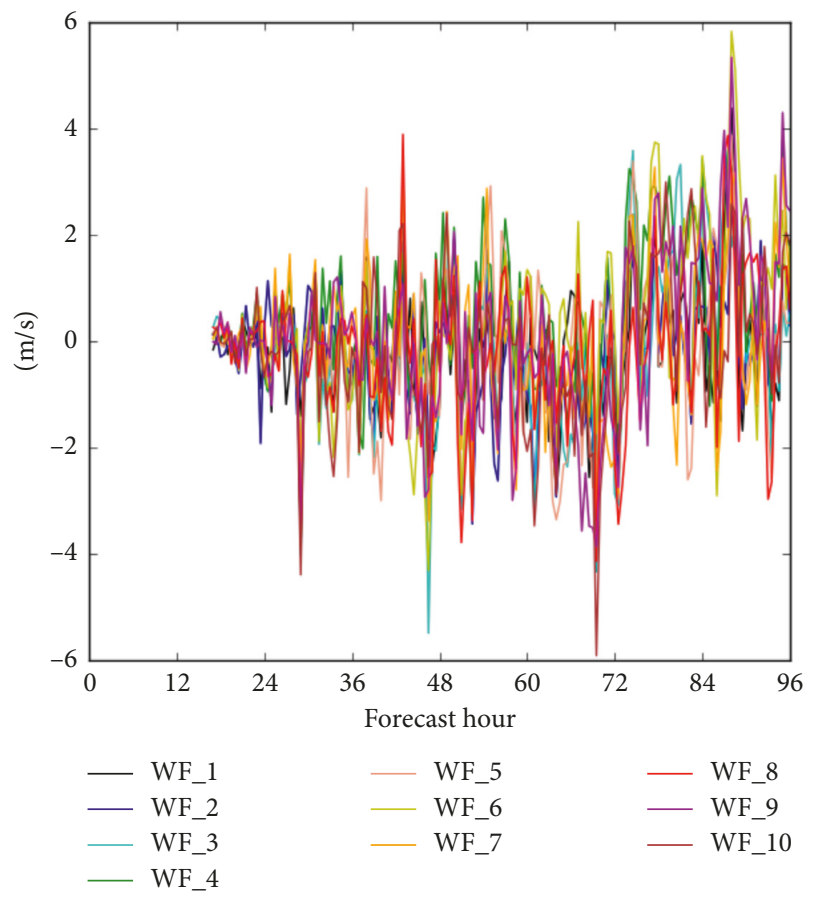

Figure 3: Example time series of cyclone maximum $10 \mathrm{~m}$ wind speed perturbation from the control run. The case shown here represents the tropical cyclone case initialized on 24 August 2011 00Z.

influencing perturbation experiments, effectively contaminating the results. In turn, it is crucial in our experiments here to address this issue if we are to understand the true relationships between wind farms and the evolution of the

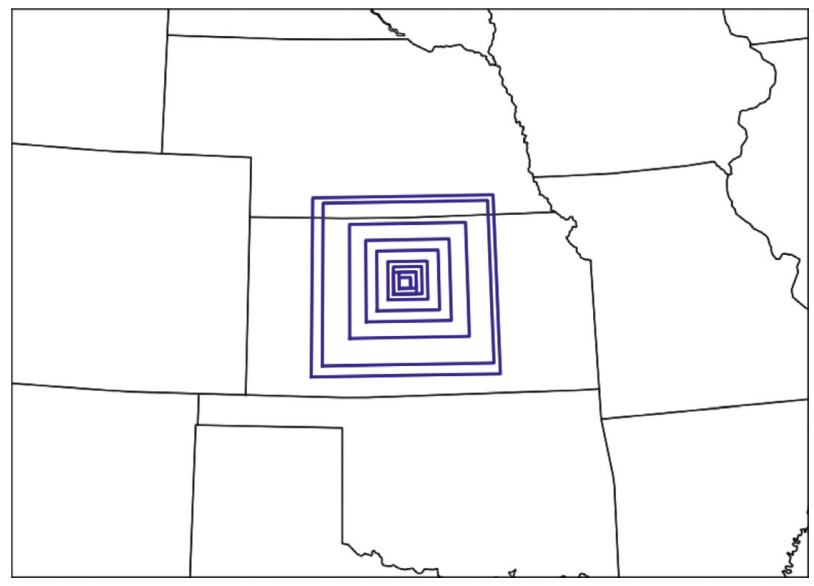

FIGURE 4: Wind farms (in outlined boxes) of the size ensemble shown for location 6 from Figure 1.

atmosphere at the time and spatial scales examined. An example of these unrealistic perturbations can be found in Figure 5. Here, the perturbations in northern Missouri at forecast hour 05 are approximately $800 \mathrm{~km}$ from the wind farm and were present in the beginning at half an hour after initialization, but at a much smaller magnitude. If realistic, the perturbations would have traveled at 1600 kilometers per hour, far too fast for the advection of realistic perturbations via gravity or acoustic waves. Several other model runs have also shown these unrealistic perturbations occurring at locations unexplainable by gravity or acoustic waves. In any case, experimental measures must be taken to ensure that no misinterpretations of downstream effects are being made associated with this discovered unrealistic propagation of noise.

To show an example of the unrealistic propagation of noise discussed above, the model is run with no wind farm but instead a small potential temperature perturbation across one grid cell in the stratosphere in the northeastern part of the domain noted by the green marker in Figure 6 . This area is selected due to the average zonal flow across the area from west to east; therefore, the stratospheric perturbation should likely advect out of the domain and not impact in a realistic way the features of importance in the domain such as the tropical and midlatitude cyclones. Instead, the same unrealistic perturbations observed with perturbations induced by wind farms again occur. An image of the unrealistic perturbations due to a stratospheric temperature perturbation can be found in Figure 6, and an image of the simulated reflectivity for the control run is shown in Figure 7. It can be seen that these perturbations in question are indeed occurring in and near a region of precipitation where moist physics is playing a crucial role. These moist processes are seen to be associated with rapid initial growth of noise through nonlinear chaos [36]. Other various model setups including altering the parameterizations used, changing the number of wind turbines per cell, varying the upper level damping layer and vertical velocity damping, and utilizing a nested domain with greater horizontal resolution over the wind farm were all unable to remove these unrealistic effects. 




FiguRe 5: Differences in surface pressure at forecast hour 05 between a wind farm run and a control run without any wind farms. Wind farms in box are centered over western Texas.

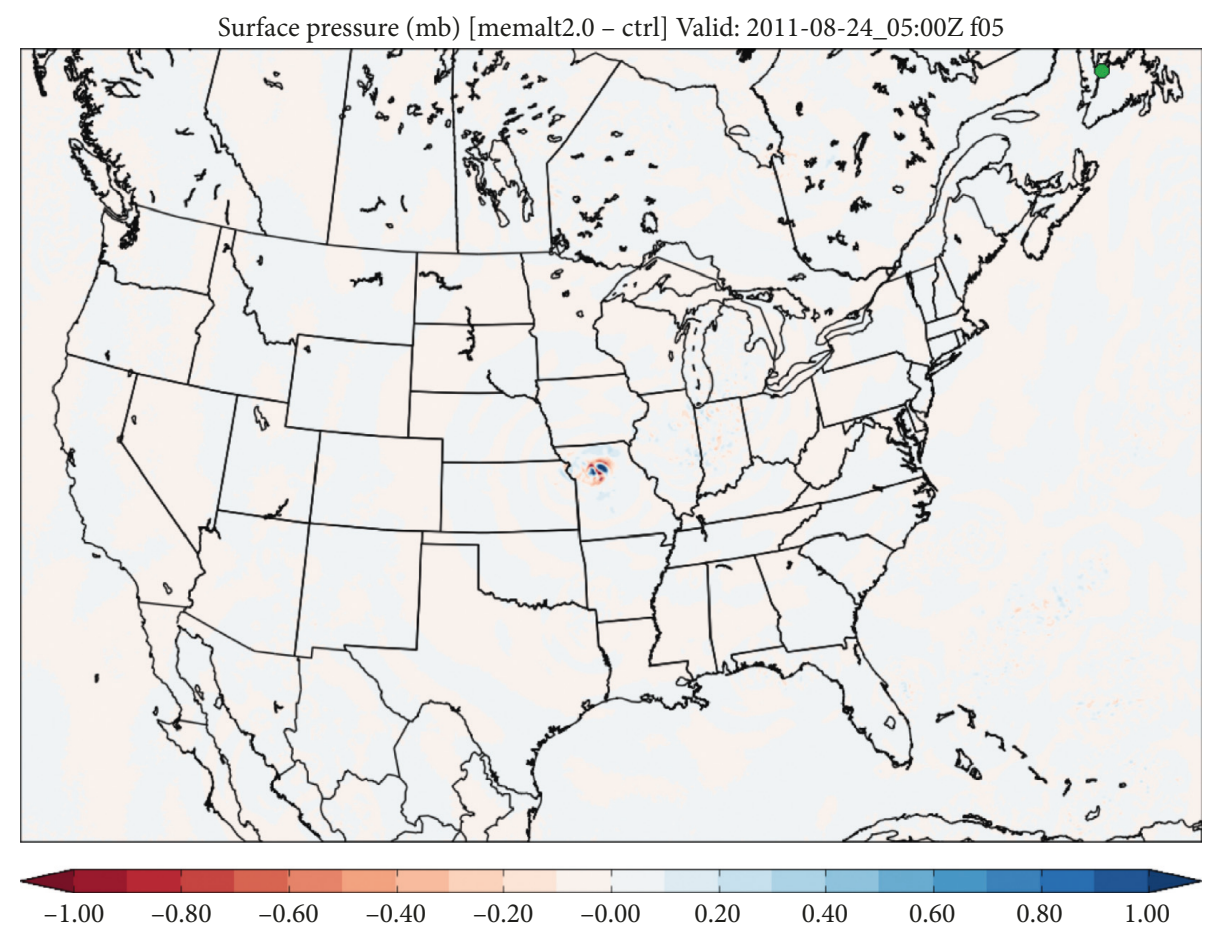

FiguRE 6: Differences in surface pressure at forecast hour 05 between a run with a $2^{\circ} \mathrm{C}$ stratospheric potential temperature perturbation and a control run. Location of temperature perturbation is shown by a green marker in the upper right part of the image.

To determine whether the results obtained from the wind farm runs are realistic and are produced by the wind farm parameterization rather than the unrealistic, rapid propagation of noise, an ensemble of ten members with varying stratospheric potential temperature perturbations is run to characterize the effects of the unrealistic perturbations. For situations where the effects from this potential temperature perturbation are not statistically different from the wind 


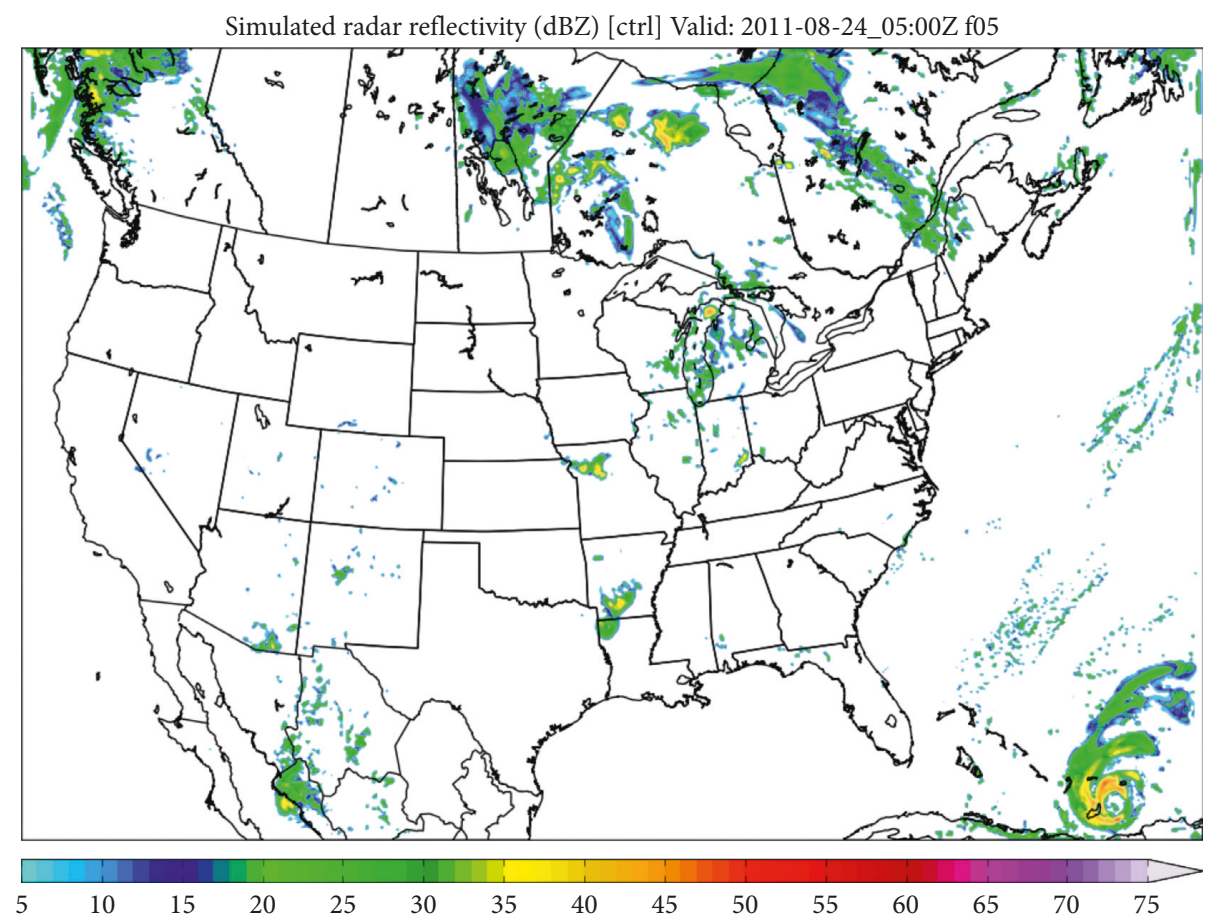

Figure 7: Simulated reflectivity at forecast hour 05 for the control run.

farm runs, we will be unable to conclude that any simulated perturbations are realistically generated from the wind farm. This technique to ensure significance results are not false positives parallel to a strategy in Lorenz et al. [37, 38], which utilized field significance testing to account for spatial correlation of results and multiplicity, and is also in line with [36] which notes there is no avoiding chaos seeding in WRF and one must account for it in the experimental setup. The ensemble here consists of potential temperature increases from the control between $0.2^{\circ} \mathrm{C}$ and $2.0^{\circ} \mathrm{C}$ in $0.2^{\circ} \mathrm{C}$ increments and will serve as the unrealistic benchmark ensemble throughout the study. All temperature increases are made in the stratosphere at an eta level of 0.240. By testing against this group of model runs with the stratospheric warming and associated unrealistic model effects, this effectively shows significance in terms of what can be concluded as realistic processes (an important aspect of the experiments as recommended in Lorenz et al. [38]). Additionally, Ancell [36] showed the unrealistic processes have no correlation with the magnitude of the perturbation in an ensemble of unrealistic runs. Thus, by testing whether the realistic ensemble shows any correlation of the metric to the initial perturbation magnitudes (and thus a sensitivity to the said magnitude), one would have shown real physical relationships beyond the more randomized noise.

The list of metrics used in this study includes both cyclone minimum sea-level pressure and maximum 10-meter wind speed, as well as cyclone maximum 30-minute accumulated precipitation, maximum and minimum 2-meter temperature, maximum and minimum 2-meter potential temperature, maximum boundary layer height, and maximum 2-meter water vapor mixing ratio. To determine whether the wind farm-induced perturbations are more significant than the unrealistic effects, linear regressions are composed between the cyclone perturbation magnitude and size of the wind farm or stratospheric potential temperature perturbation. These linear regressions will determine whether the perturbations to the cyclone show any relationship to the wind farms beyond the unrealistic effects of the noise described above, a technique also used in [36].

\section{Results}

3.1. Tropical Cyclone Example. Selected surface pressure perturbations for the 3 October 2013 tropical cyclone case are shown in Figure 8, and Figure 9 shows the sea-level pressure and $10 \mathrm{~m}$ wind for the control run. Beginning at forecast hour 05, perturbations across the domain are restricted to within and near the wind farm in Oklahoma. Here, a southerly flow in the wind farm region led to a positive pressure perturbation along the southern edge of the wind farm and extending through the wind farm due to propagation of the perturbation. Downwind, a negative pressure perturbation existed at the northern edge of the farm and propagated northward with the flow. By forecast hour 24, the southerly flow has moved pressure perturbations created by the wind farm as far north as Canada. The pressure perturbations at this time were not well organized; but by forecast hour 42 , it can be seen that the perturbations were beginning to organize.

At forecast hour 64, the pressure perturbation dipole suggests a positional change of the tropical cyclone between the control run and model run with the wind farm. These dipole pressure perturbations are common throughout many cases in the forecast hour range of 48-96 and may be a systematic effect of wind farms on cyclones. However, 
Surface pressure (mb) [mem4 - ctrl] Valid: 2013-10-03_05:00Z f05

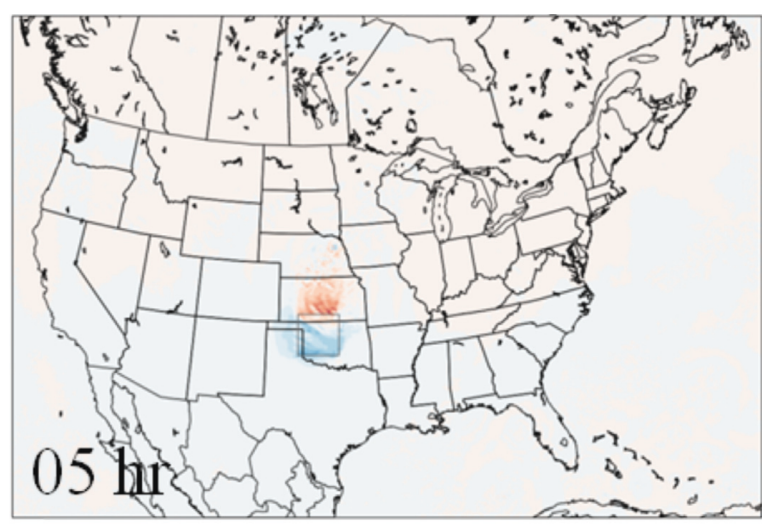

$-1.00-0.80-0.60-0.40-0.20-0.00 \quad 0.20 \quad 0.40 \quad 0.60 \quad 0.80 \quad 1.00$

(a)

Surface pressure (mb) [mem4 - ctrl] Valid: 2013-10-04_18:00Z f42

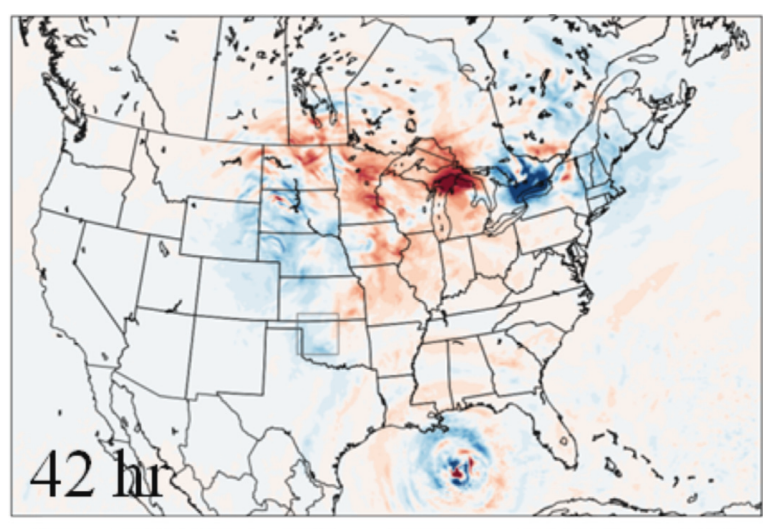

$-1.00-0.80-0.60-0.40-0.20-0.00 \quad 0.20 \quad 0.40 \quad 0.60 \quad 0.80 \quad 1.00$

(c)

Surface pressure (mb) [mem4 - ctrl] Valid: 2013-10-06_10:00Z f82

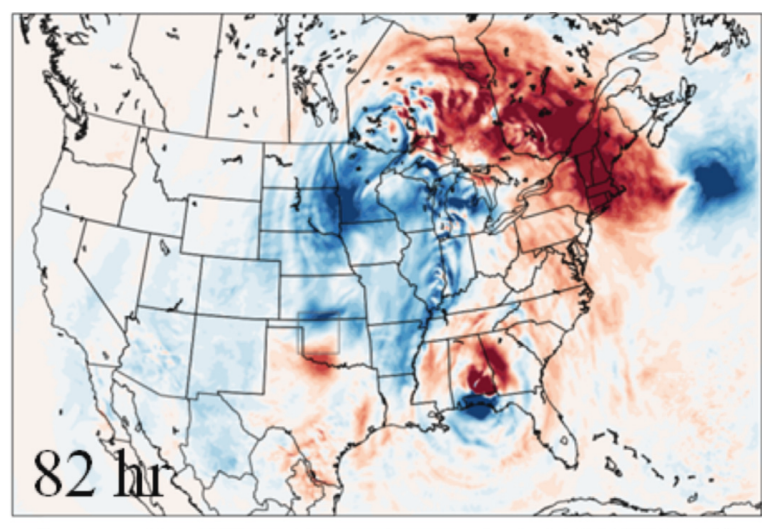

$-1.00-0.80-0.60-0.40-0.20-0.00 \quad 0.20 \quad 0.40 \quad 0.60 \quad 0.80 \quad 1.00$

(e)
Surface pressure (mb) [mem4 - ctrl] Valid: 2013-10-04_00:00Z f24

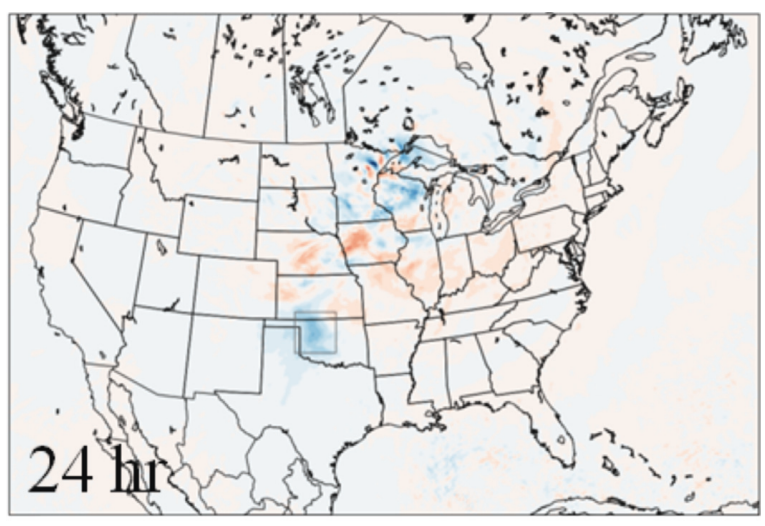

$-1.00-0.80-0.60-0.40-0.20-0.00 \quad 0.20 \quad 0.40 \quad 0.60 \quad 0.80 \quad 1.00$

(b)

Surface pressure (mb) [mem4 - ctrl] Valid: 2013-10-05_16:00Z f64

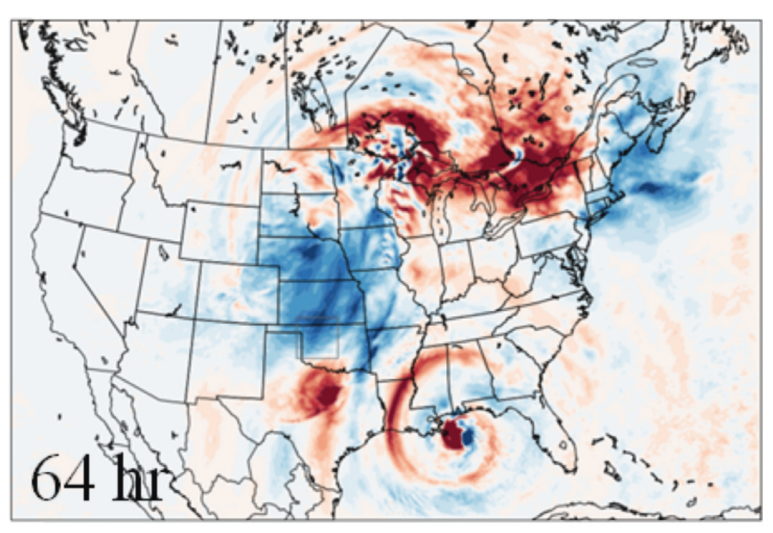

$-1.00-0.80-0.60-0.40-0.20-0.00 \quad 0.20 \quad 0.40 \quad 0.60 \quad 0.80 \quad 1.00$

(d)

Surface pressure (mb) [mem4 - ctrl] Valid: 2013-10-07_00:00Z f96

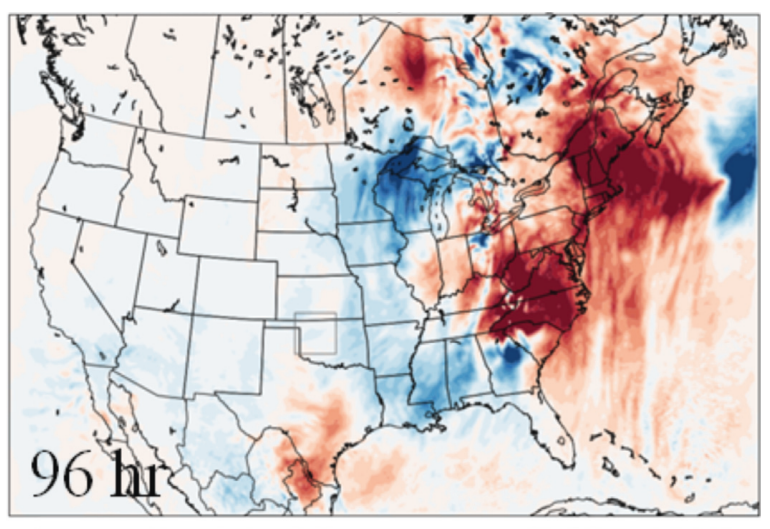

$-1.00-0.80-0.60-0.40-0.20-0.00 \quad 0.20 \quad 0.40 \quad 0.60 \quad 0.80 \quad 1.00$

(f)

Figure 8: Surface pressure perturbations at forecast hours 05 (a), 24 (b), 42 (c), 64 (d), 82 (e), and 96 (f) for the 3 October 2013 case due to a wind farm in box shown in Oklahoma. 


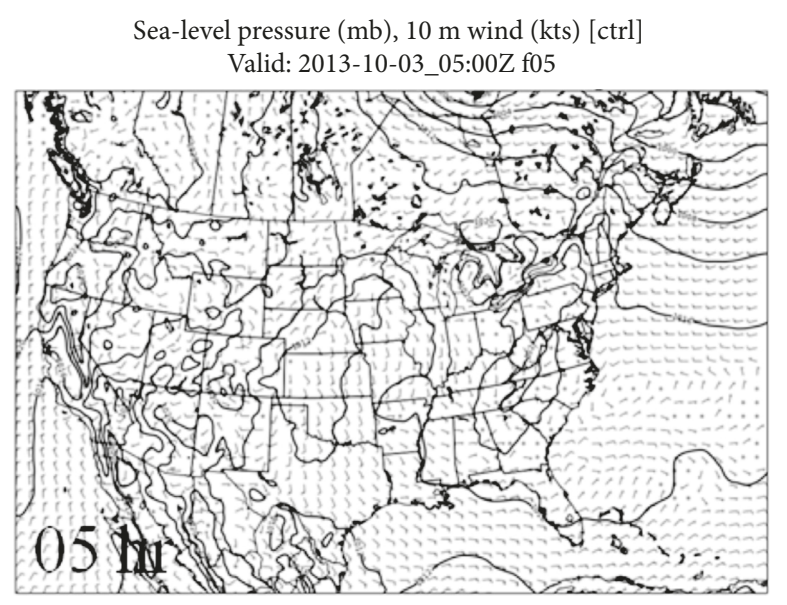

(a)

Sea-level pressure (mb), $10 \mathrm{~m}$ wind (kts) [ctrl] Valid: 2013-10-04_18:00Z f42

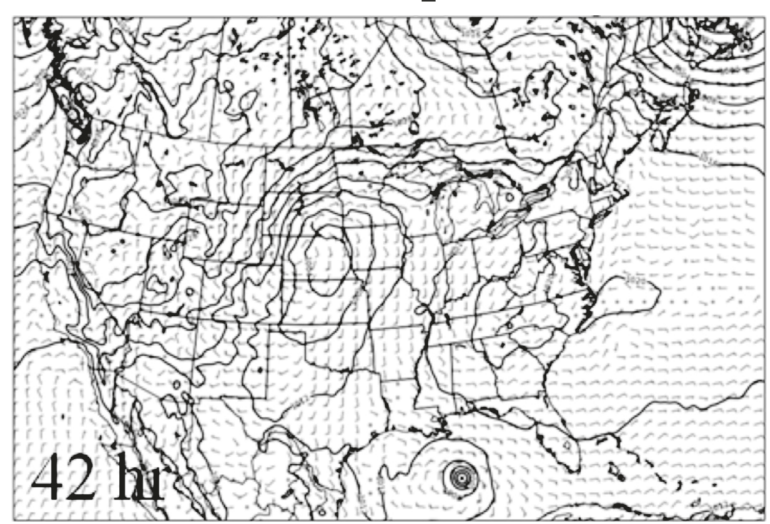

(c)

Sea-level pressure (mb), $10 \mathrm{~m}$ wind (kts) [ctrl] Valid: 2013-10-06 10:00Z f82

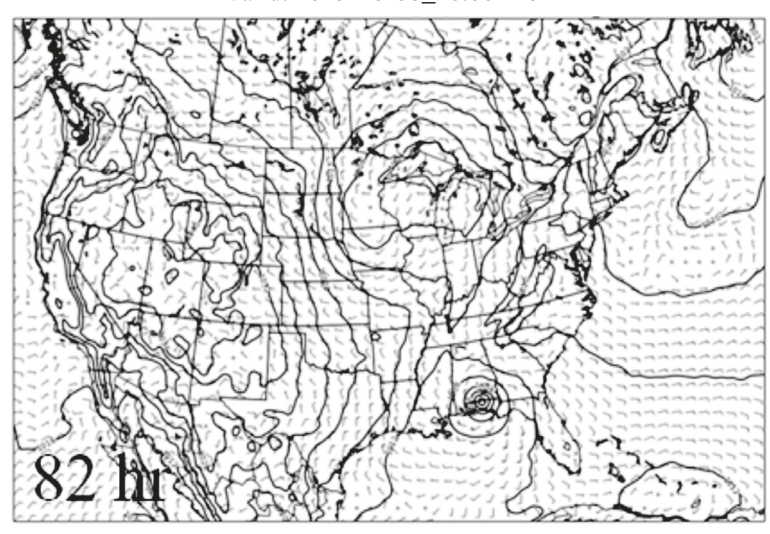

(e)

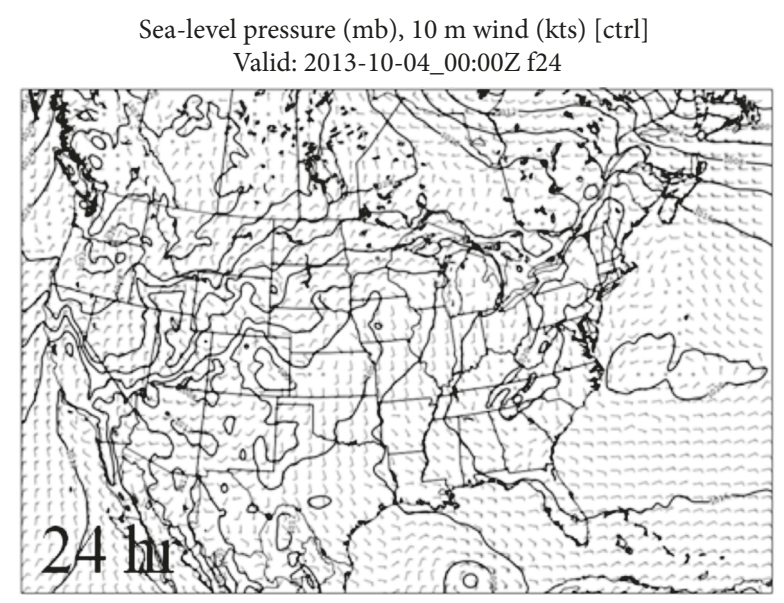

(b)

Sea-level pressure (mb), $10 \mathrm{~m}$ wind (kts) [ctrl] Valid: 2013-10-05_16:00Z f64

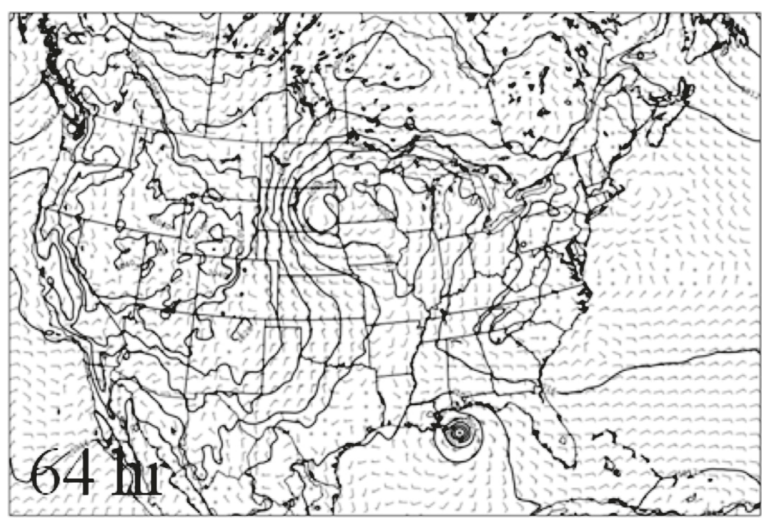

(d)

Sea-level pressure (mb), $10 \mathrm{~m}$ wind (kts) [ctrl] Valid: 2013-10-07_00:00Z f96

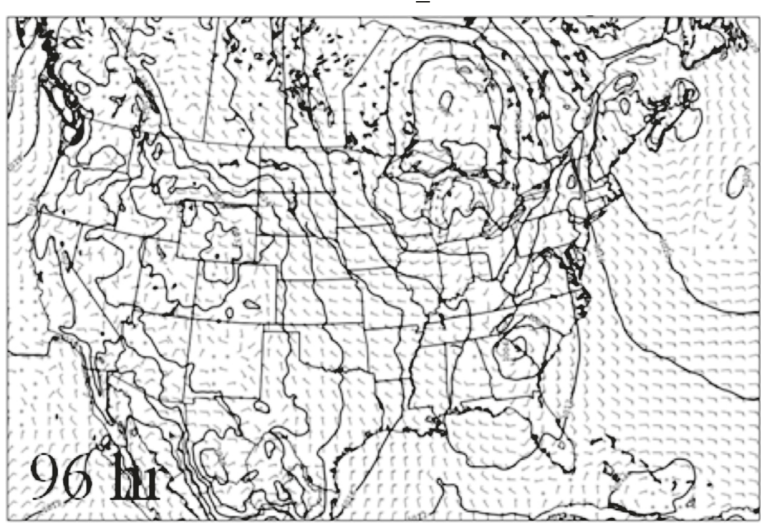

(f)

FIgURE 9: Surface sea-level pressure and $10 \mathrm{~m}$ wind speed at forecast hours 05 (a), 24 (b), 42 (c), 64 (d), 82 (e), and 96 (f) for the 3 October 2013 control case.

these systematic effects are not consistent in each case, as the cyclone track change is dependent on many factors including wind farm location, cyclone location, and cyclone intensity. Also, the waves emanating from the tropical cyclone evident in the figure are regarded as realistic perturbations, likely due to gravity waves. These are not the unrealistic model effects that occur instantaneously at model initiation throughout the entire domain discussed previously. By the end of the forecast, the tropical cyclone pressure perturbations have interacted with perturbations in the larger synoptic flow, presenting a negative perturbation to pressure. It is also worth noting that the perturbations are 
almost entirely limited to along the longitude of the wind farm and eastward, due to the west-to-east synoptic zonal flow across the United States.

3.2. Midlatitude Cyclone Example. Examining the surface pressure perturbations for the 26 April 2014 midlatitude cyclone case also reveals similar features as the tropical cyclone case above. An area of increased pressure formed on the upwind side of the wind farm in Kansas, in this case the southern side, and a resulting low pressure perturbation occurred on the northern side of the wind farm. One explanation for this is with more mass accumulating on the upwind side of wind farms due to interaction with turbines, a decreased pressure forms on the downwind side due to conservation of mass, as seen at forecast hour 05 in Figure 10. Another possible mechanism for the pressure perturbation signature is a gravity wave caused by the divergence and convergence pattern around the wind farm [12]. For reference, the sea-level pressure and $10 \mathrm{~m}$ wind for the control run are shown in Figure 11. The decreased pressure perturbation advanced with the flow to the northeast and began to interact with unrealistic perturbations by forecast hour 16. Cyclogenesis began in northeastern Colorado shortly afterward, and the area of increased pressure stayed in place.

By forecast hour 40, the cyclone that developed in Colorado had moved eastward and became modified by the wind farm-induced perturbations. The cyclone pressure was increased due to the presence of the increased pressure perturbation in the area. Throughout the remainder of the forecast, the midlatitude cyclone continued to exhibit an increased pressure due to the wind farm in Kansas. A feature of decreased pressure in northern Wisconsin interacted with the cyclone in forecast hours 80 through 96 as the cyclone continued to progress northeastward.

The positioning of the wind farm is likely very important for midlatitude cyclone perturbations, as midlatitude cyclogenesis occurs near the wind farms. The sign and magnitude of perturbations to the cyclone are dependent on the flow direction, as the positive and negative pressure perturbations are formed on the upwind and downwind sides of the wind farm, respectively. The advancement of these perturbations to the area of cyclogenesis or to the cyclone's path appears to result in the precise sign of pressure perturbation realized by the cyclone.

3.3. Sensitivity to Wind Farm Location. The perturbations caused by wind farms appear to have an impact on nonlocal atmospheric features downwind of the farm and are able to modify high-impact features as seen in Figures 8 and 10 . However, simply examining differences between the control and perturbed runs may be misleading due to the effects of unrealistic noise in the model. Thus, the cyclones in these simulations are analyzed objectively to determine how they are affected by wind farms. First, time-series plots were utilized to determine which wind farm locations are in regions most sensitive to cyclogenesis, cyclone propagation, and cyclolysis. The member of the ensemble that produced the most significant changes to cyclone is chosen as the location in which the ensemble of wind farm sizes is run. The two metrics chosen due to their close association with cyclone intensity include the cyclone minimum mean sea-level pressure and maximum $10 \mathrm{~m}$ wind speed. The time-series plots of one tropical cyclone and one midlatitude cyclone for these variables are shown in Figures 12 and 13, showing model runs with the ten different wind farm locations included in the location ensemble and how that location influences the cyclone perturbations. The location that produces the largest perturbations over the extended forecast period is chosen as the location to run the ensemble of wind farm sizes. Another impact of wind farms on cyclones considered by this study is the cyclone track itself. Figure 14 shows the cyclone track for all ten wind farm location runs as well as the control for the cyclones considered in Figures 12 and 13. Little change in the cyclone track was noticed for all cyclones in this study, and further analysis focuses on the intensity-based metrics introduced above, as well as other metrics that are described later.

3.4. Sensitivity to Wind Farm Size. With the wind farm locations determined to have the largest impacts on the cyclone development, the ensemble of wind farm sizes is then run to determine the dependency of nonlocal perturbation magnitude on the wind farm size. Locations where the wind farm size ensemble is run for each case are shown in Table 1. Table 2 shows the sizes of the wind farms used for the size ensemble. The largest perturbations over the forecast for each of the ten wind farm sizes are compared to determine the trend between perturbation magnitude and sign and the wind farm size. Statistical analysis in the form of the coefficient of determination, $r^{2}$, is utilized to determine how well the perturbations with varying wind farm sizes fit a linear regression line. The slope of the linear regression is also analyzed, and a $p$ value is calculated to determine the statistical significance of that slope relative to the null hypothesis that there exists no relationship between the chosen metrics and the wind farm size.

Arguably, the most important metric to determine the strength of cyclones is the minimum sea-level pressure. When comparing wind farm size and the perturbation to cyclone minimum sea-level pressure, unique trends appear. Generally for tropical cyclones, the wind farm decreases the central cyclone pressure. Also, three of four tropical cyclone cases show that the minimum pressure perturbation becomes more negative with increasing wind farm size, while one case showed the opposite trend.

On the contrary, when it comes to midlatitude cyclones, the opposite is usually true. In five of six cases, most wind farm sizes increase the minimum sea-level pressure in the cyclone, thus weakening the midlatitude cyclone. Four of the six cases also show that the minimum pressure perturbation becomes more positive with increasing wind farm size. Shown in Figures 15 and 16 are the largest minimum sealevel pressure perturbations that occur with the ten wind farm sizes, the linear regression for these perturbations, and statistical values for the tropical and midlatitude cyclones 
Surface pressure (mb) [mem6 - ctrl] Valid: 2014-04-26 05:00Z f05

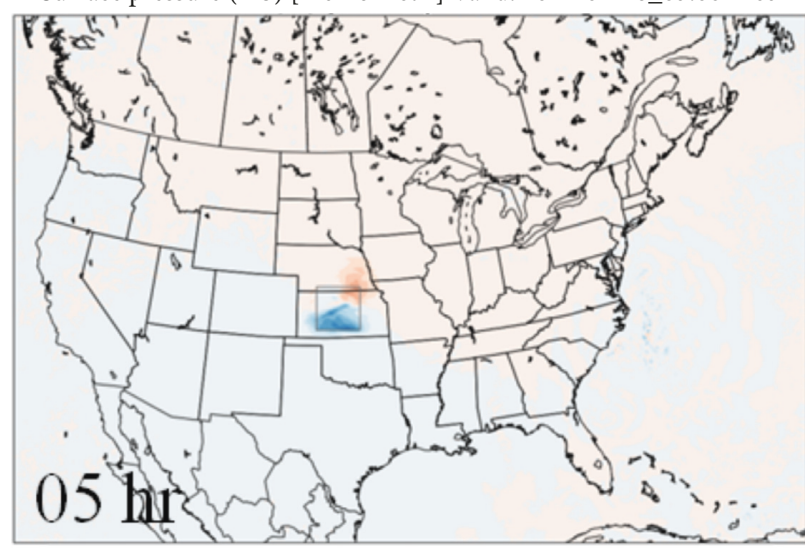

$\begin{array}{lllllllllll}-1.00 & -0.80 & -0.60 & -0.40 & -0.20 & -0.00 & 0.20 & 0.40 & 0.60 & 0.80 & 1.00\end{array}$

(a)

Surface pressure (mb) [mem6 - ctrl] Valid: 2014-04-27_16:00Z f40

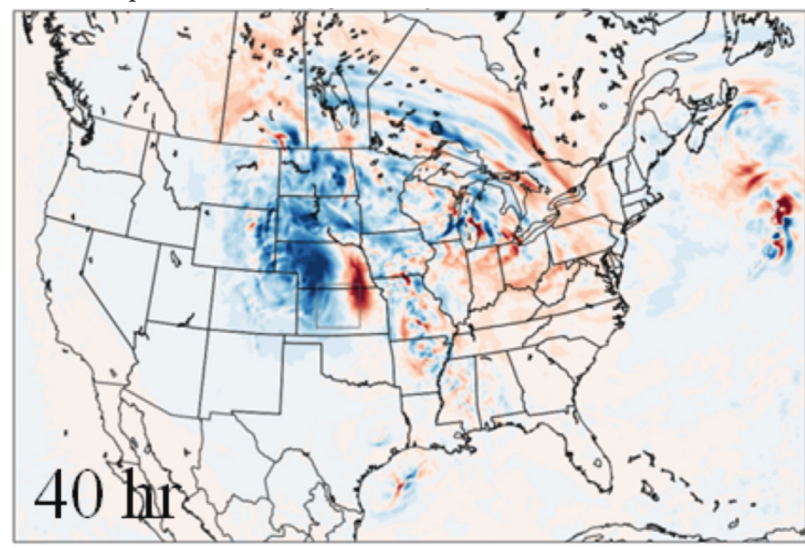

$\begin{array}{lllllllllll}-1.00 & -0.80 & -0.60 & -0.40 & -0.20 & -0.00 & 0.20 & 0.40 & 0.60 & 0.80 & 1.00\end{array}$

(c)

Surface pressure $(\mathrm{mb})$ [mem6 - ctrl] Valid: 2014-04-29_08:00Z f80

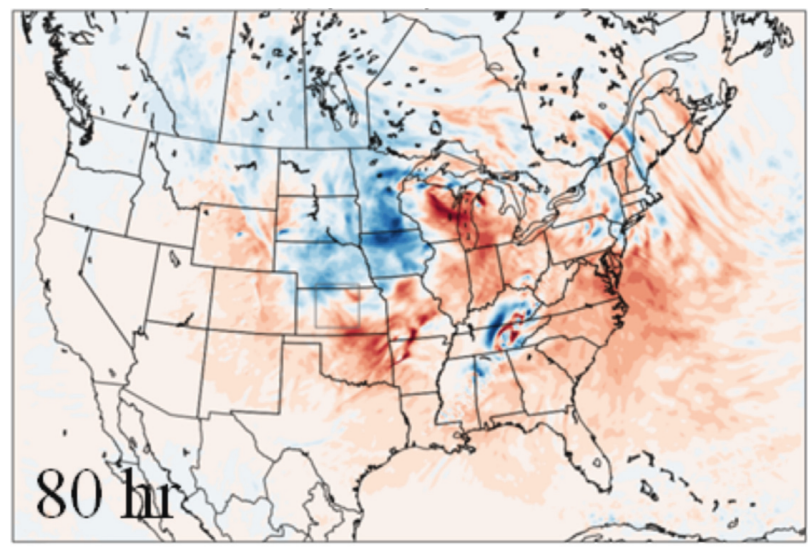

$\begin{array}{lllllllllll}-1.00 & -0.80 & -0.60 & -0.40 & -0.20 & -0.00 & 0.20 & 0.40 & 0.60 & 0.80 & 1.00\end{array}$

(e)
Surface pressure (mb) [mem6 - ctrl] Valid: 2014-04-26 16:00Z f16

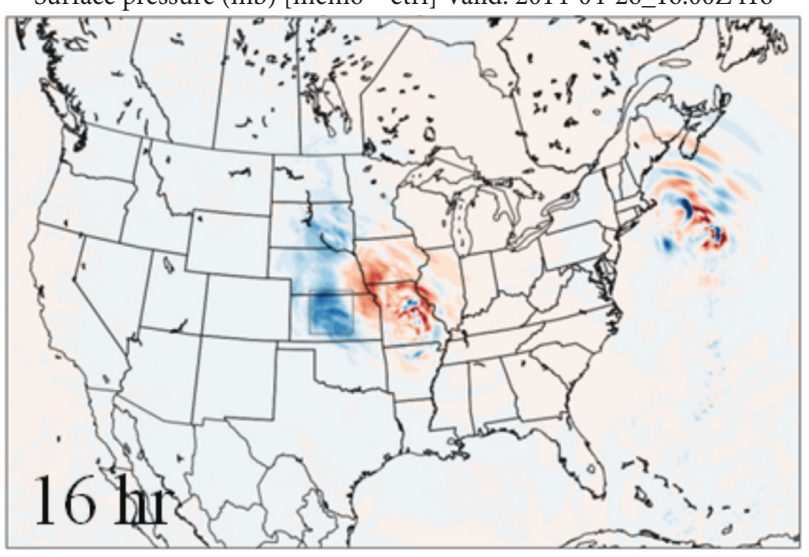

$\begin{array}{lllllllllll}-1.00 & -0.80 & -0.60 & -0.40 & -0.20 & -0.00 & 0.20 & 0.40 & 0.60 & 0.80 & 1.00\end{array}$

(b)

Surface pressure $(\mathrm{mb})$ [mem6 - ctrl] Valid: 2014-04-28_14:00Z f62

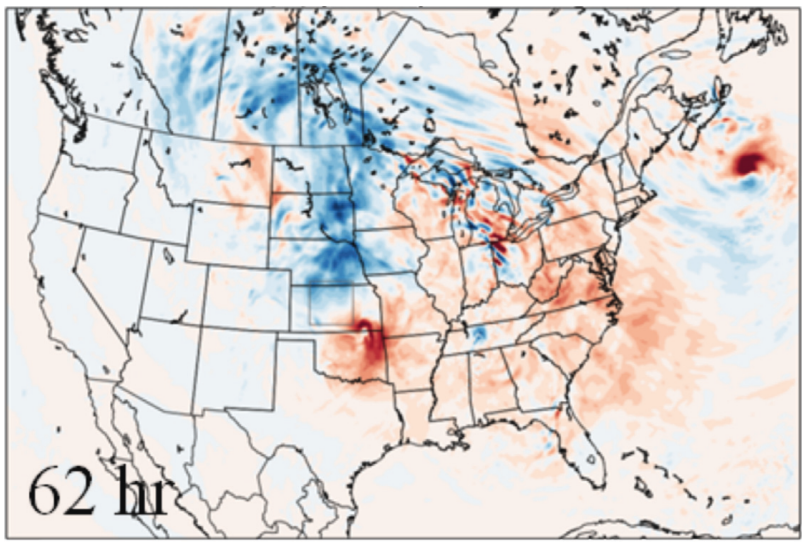

$\begin{array}{lllllllllll}-1.00 & -0.80 & -0.60 & -0.40 & -0.20 & -0.00 & 0.20 & 0.40 & 0.60 & 0.80 & 1.00\end{array}$

(d)

Surface pressure $(\mathrm{mb})$ [mem6 - ctrl] Valid: 2014-04-30_00:00Z f96

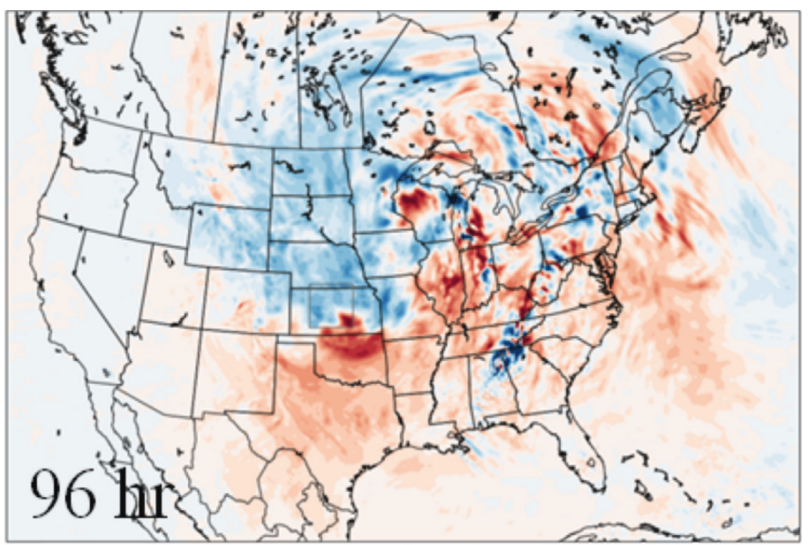

$\begin{array}{lllllllllll}-1.00 & -0.80 & -0.60 & -0.40 & -0.20 & -0.00 & 0.20 & 0.40 & 0.60 & 0.80 & 1.00\end{array}$

(f)

Figure 10: Surface pressure perturbations at forecast hours 05 (a), 16 (b), 40 (c), 62 (d), 80 (e), and 96 (f) for the 26 April 2014 case due to a wind farm in box shown in Kansas. 


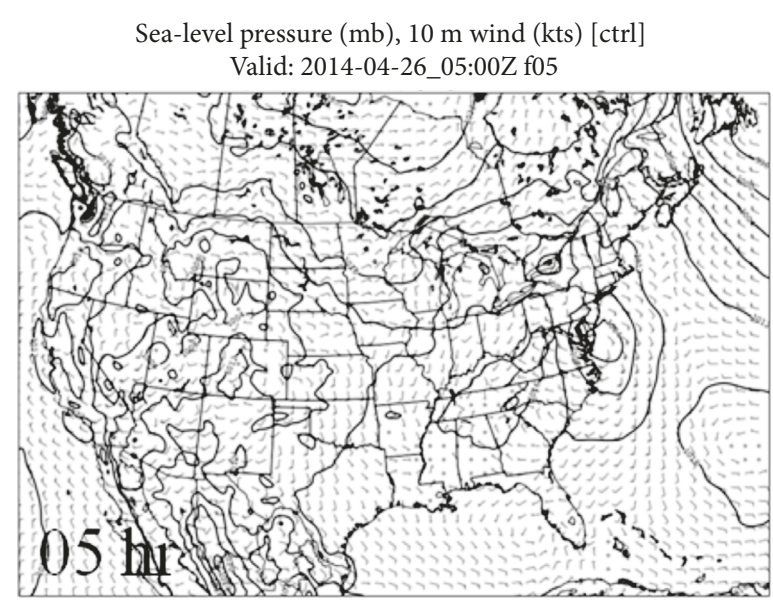

(a)

Sea-level pressure (mb), $10 \mathrm{~m}$ wind (kts) [ctrl] Valid: 2014-04-27_16:00Z f40

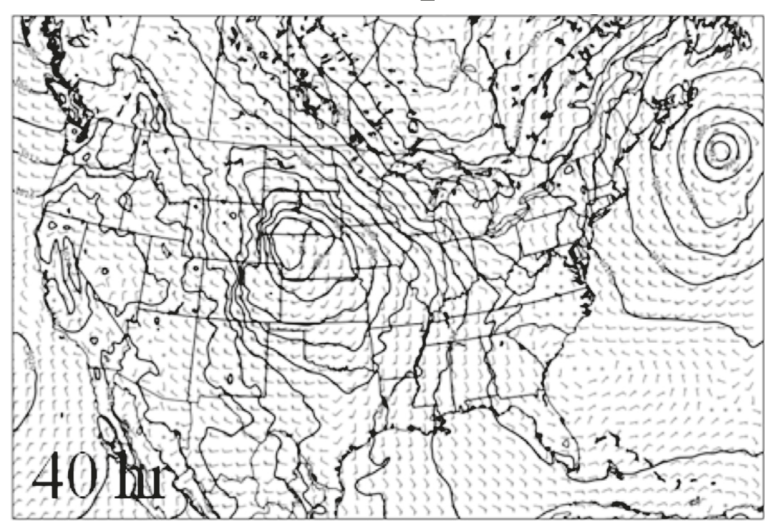

(c)

Sea-level pressure (mb), $10 \mathrm{~m}$ wind (kts) [ctrl] Valid: 2014-04-29 08:00Z f80

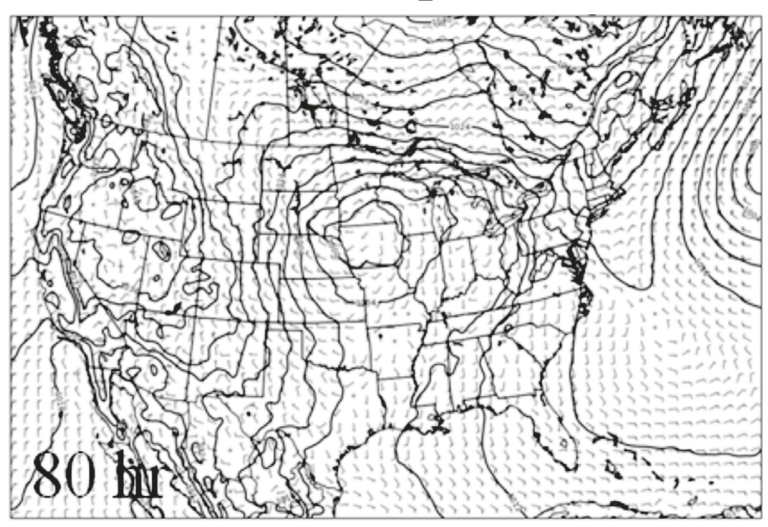

(e)

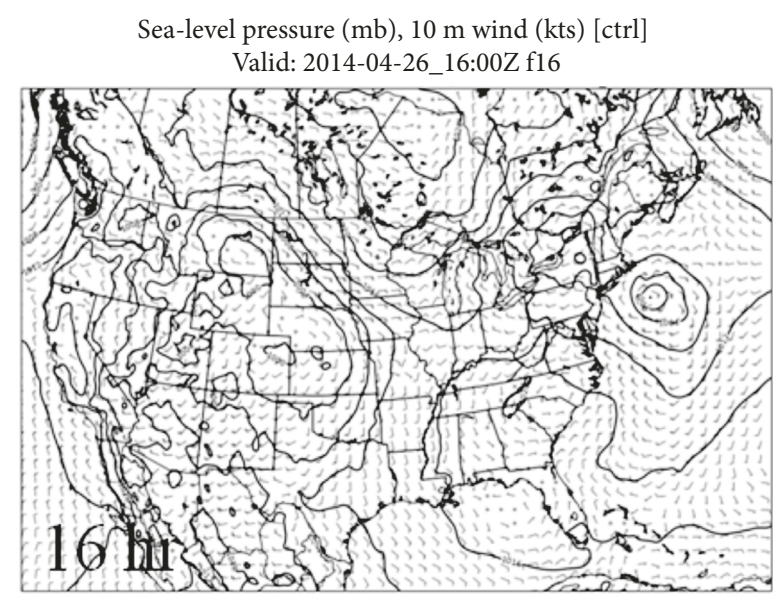

(b)

Sea-level pressure (mb), $10 \mathrm{~m}$ wind (kts) [ctrl] Valid: 2014-04-28_14:00Z f62

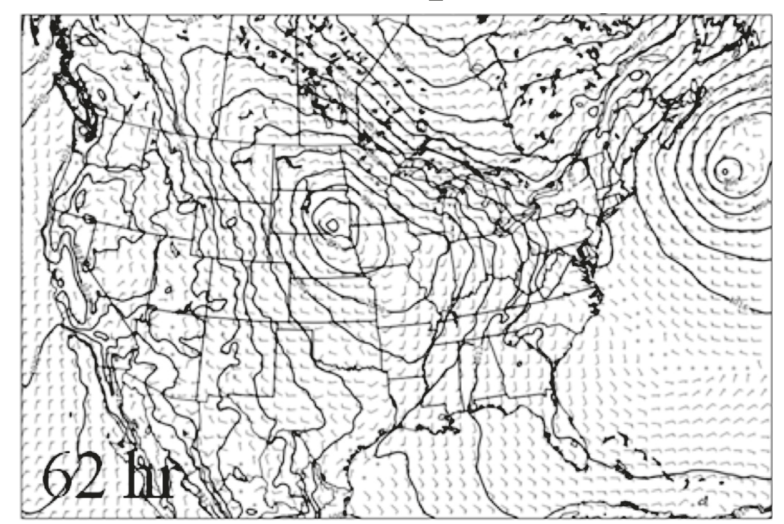

(d)

Sea-level pressure (mb), $10 \mathrm{~m}$ wind (kts) [ctrl] Valid: 2014-04-30 00:00Z f96

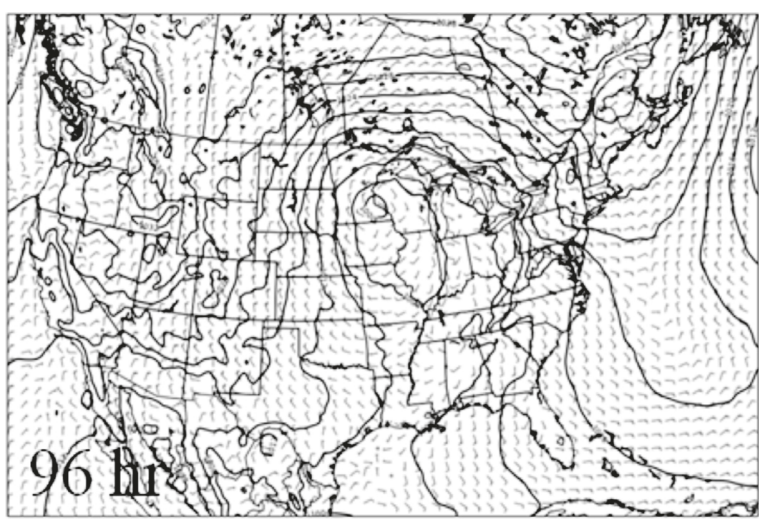

(f)

FiguRE 11: Surface sea-level pressure and $10 \mathrm{~m}$ wind speed at forecast hours 05 (a), 16 (b), 40 (c), 62 (d), 80 (e), and 96 (f) for the 26 April 2014 control case.

covered earlier. Each dot shows one model run and how the wind farm size (or magnitude of unrealistic temperature perturbation) corresponds to the magnitude of perturbation to the cyclone. The linear relationship shown in the midlatitude cyclone case (Figure 16) with varying wind farm sizes shows the relationship between wind farm size and cyclone central pressure is significant, unlike the tropical cyclone case shown in Figure 15 or either of the unrealistic ensembles. In this case, the five largest-sized wind farms produced a noticeable change to the midlatitude cyclone.

Multiple cases show a relationship between the magnitude of cyclone minimum sea-level pressure and the wind 


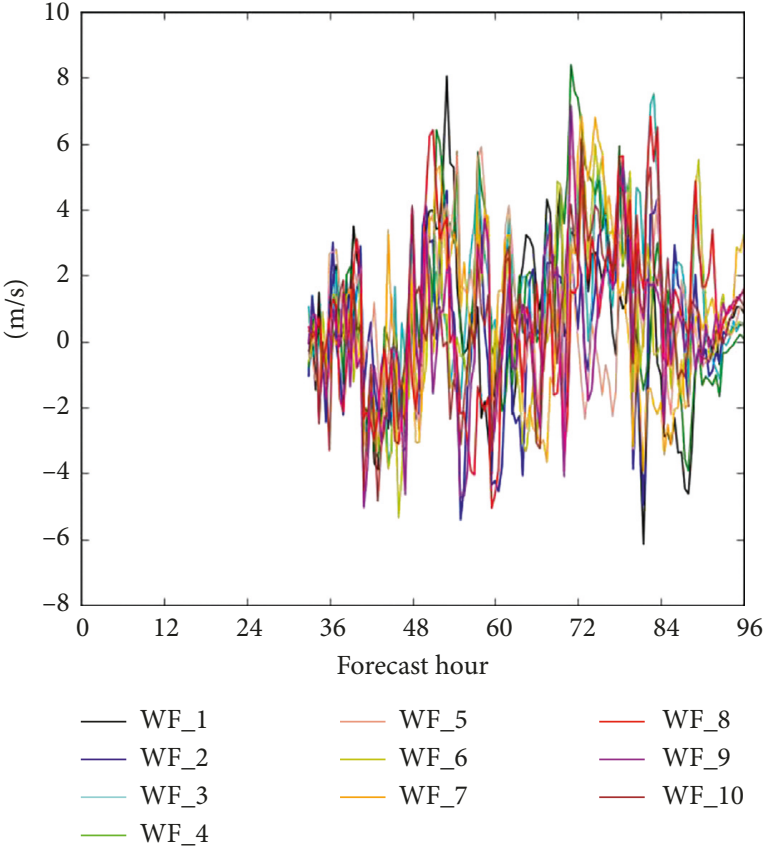

(a)

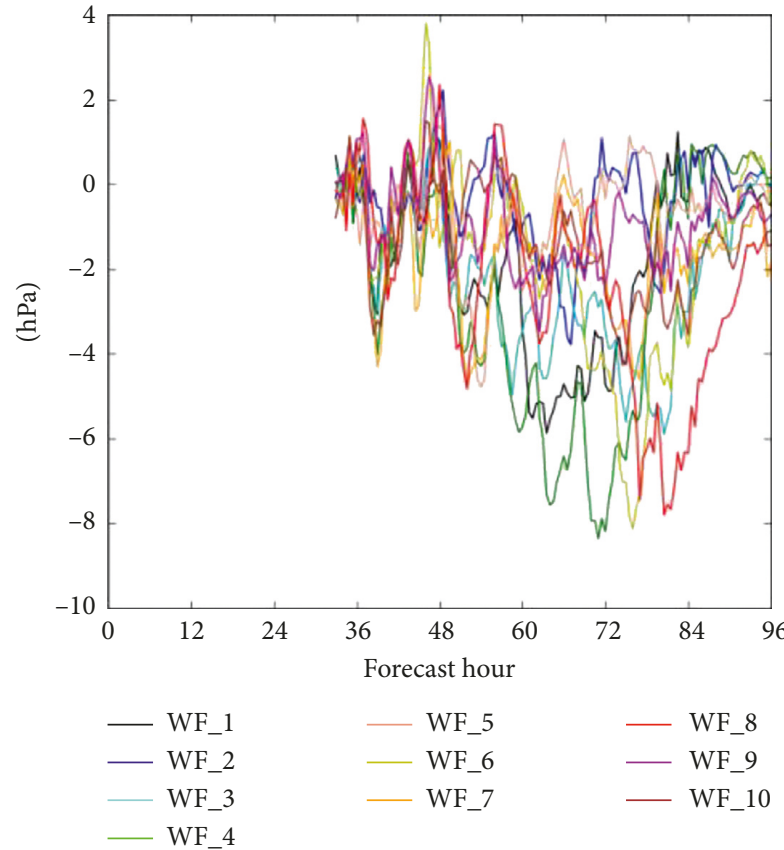

(b)

Figure 12: Cyclone maximum $10 \mathrm{~m}$ wind speed (a) and minimum sea-level pressure perturbation (b) for the 3 October 2013 tropical cyclone case.

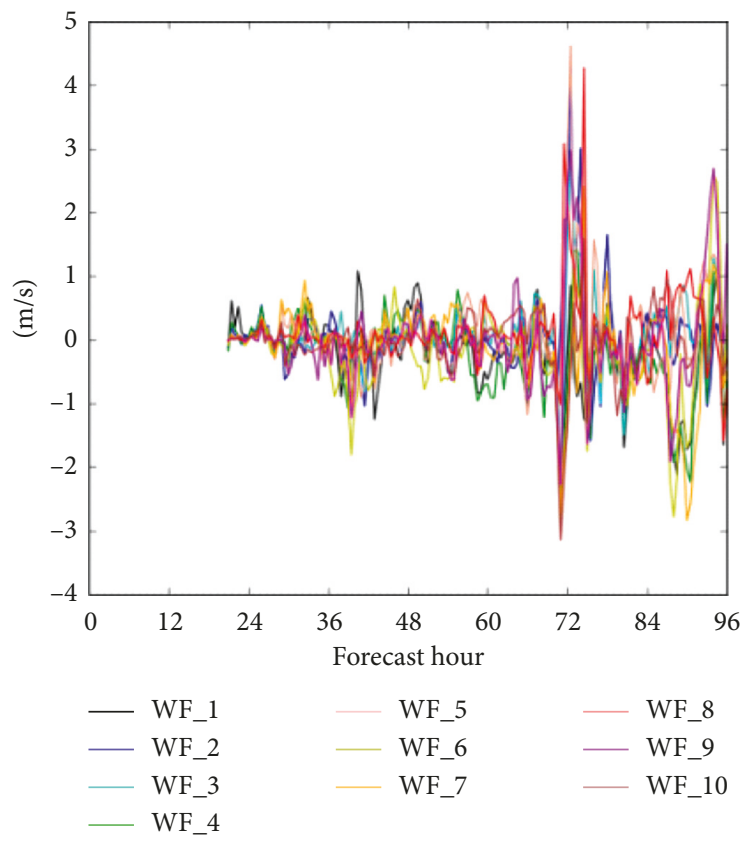

(a)

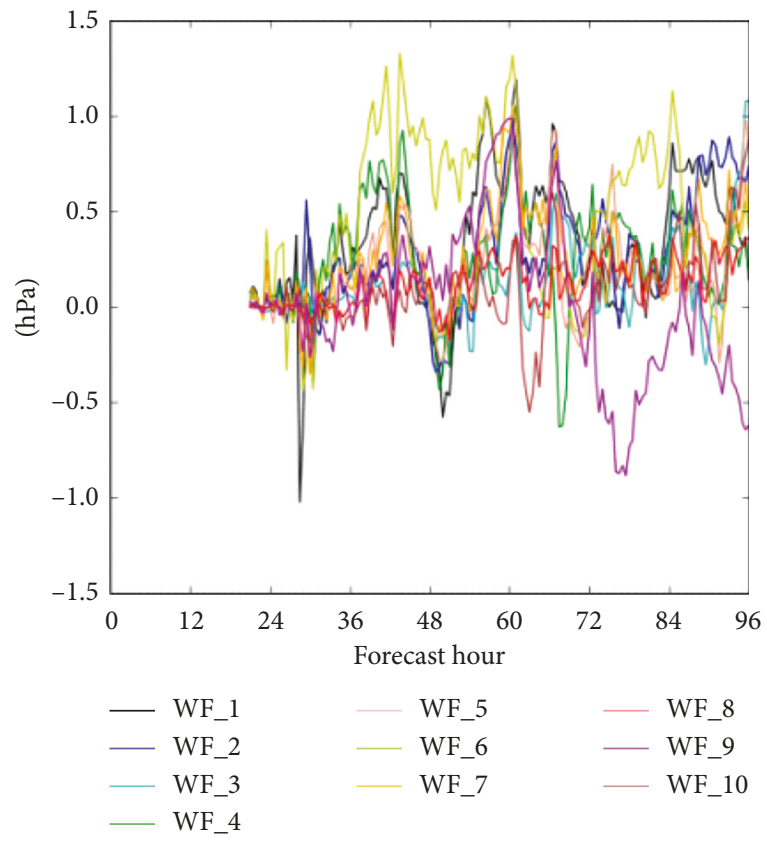

(b)

FIGURE 13: Cyclone maximum $10 \mathrm{~m}$ wind speed (a) and minimum sea-level pressure perturbation (b) for the 26 April 2014 midlatitude cyclone case.

farm size-five of the six midlatitude cases showed a significant $p$ value (equal to or less than 0.05 ), while none of the tropical cyclone cases did. The average $p$ value for midlatitude cyclones is 0.1043 , while the average $p$ value for tropical cyclones is 0.5229, shown in Tables 3 and 4 .
Additionally, the coefficient of determination $\left(r^{2}\right)$ shows many cases where the data fit a linear regression well. The average $r^{2}$ value for midlatitude cyclones is 0.5900, while the average $r^{2}$ value for tropical cyclones is 0.0961 , also shown in Tables 3 and 4. Again, these statistics are calculated for each 


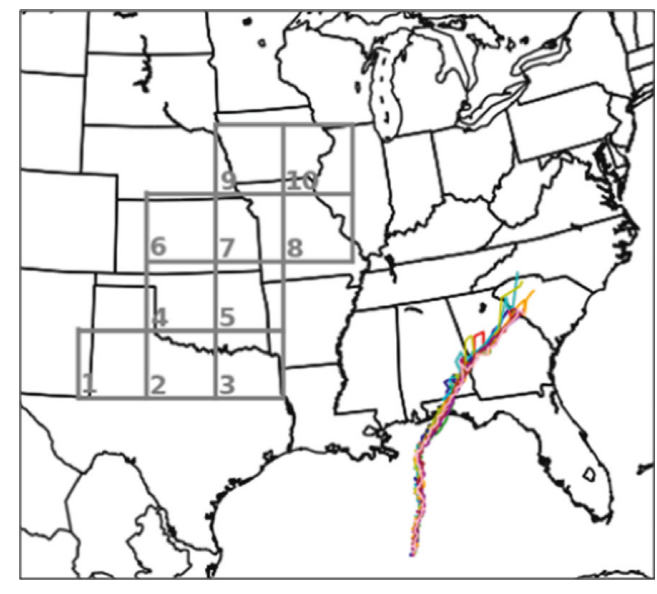

(a)

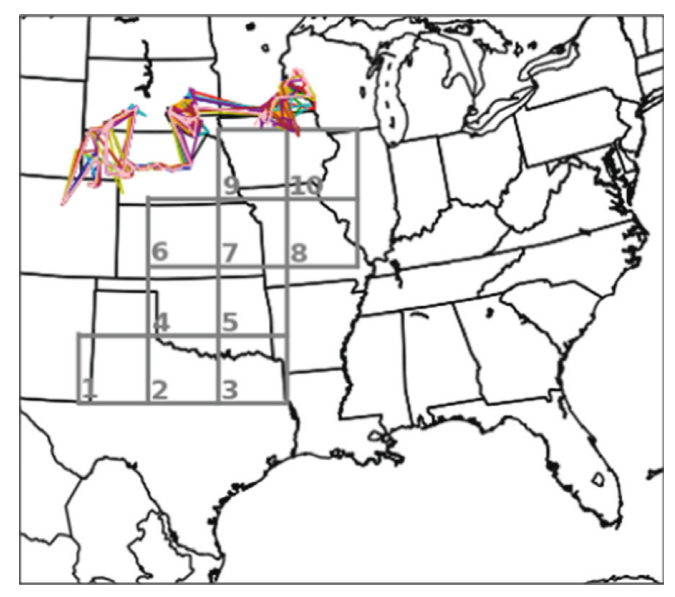

(b)

Figure 14: Cyclone tracks for the control (black) and wind farm location ensemble members (color) for the 3 October 2013 tropical cyclone (a) and 26 April 2014 midlatitude cyclone (b). Wind farm locations are outlined in gray.

case (six midlatitude and four tropical), among all ten members of the wind farm size ensemble, and averaged among all cases. The $r^{2}$ value is simply a linear regression and therefore is a measure of how consistently the perturbation magnitude is changed as the wind farm size changes. The $p$ value here indicates how significant this linear regression is compared to no change at all. These statistical tests are also applied to all other metrics included in the study and are also summarized in Tables 3 and 4.

Another important metric for determining cyclone strength, especially tropical cyclones, is wind speed. The maximum $10 \mathrm{~m}$ wind speed increased in three of the four tropical cyclone cases due to a wind farm in the Central United States. Among these four cases, increasing the size of the wind farm increased wind speeds in two cases and decreased the maximum wind speed in the other two cases. Four of the six midlatitude cyclones observed increases in maximum wind speed with a wind farm in the model. Also, five of the six midlatitude cyclones realized greater maximum wind speed with increasing wind farm size. The average $r^{2}$ value for midlatitude cyclones is 0.2984 , while the average $r^{2}$ value for tropical cyclones is 0.0803 . The average $p$ value for midlatitude cyclones is 0.2566 , while the average $p$ value for tropical cyclones is 0.3487 .

When considering weather that has a large impact on the safety and protection of life and property, rainfall and flooding rank among the most powerful ones. Here, we analyze the maximum 30-minute accumulated precipitation at the same grid point within the cyclone. The maximum 30minute accumulated precipitation is seen to increase in two tropical cyclone cases and additionally in another only for the largest wind farms. Among these four cases, increasing the size of the wind farm increased maximum 30-minute accumulated precipitation in two cases, and the other two cases saw a decrease in maximum 30-minute accumulated precipitation with larger wind farms. Three of the six midlatitude cyclones observed increases in maximum 30minute accumulated precipitation with a wind farm in the model, and the other three cases realized increases to
TABLE 2: Wind farm size ensemble member sizes.

\begin{tabular}{lc}
\hline Dimensions & Number of turbines \\
\hline $20 \mathrm{~km} \times 20 \mathrm{~km}$ & 1,296 \\
$30 \mathrm{~km} \times 30 \mathrm{~km}$ & 2,916 \\
$40 \mathrm{~km} \times 40 \mathrm{~km}$ & 5,184 \\
$50 \mathrm{~km} \times 50 \mathrm{~km}$ & 8,100 \\
$70 \mathrm{~km} \times 70 \mathrm{~km}$ & 15,876 \\
$110 \mathrm{~km} \times 110 \mathrm{~km}$ & 39,204 \\
$150 \mathrm{~km} \times 150 \mathrm{~km}$ & 72,900 \\
$210 \mathrm{~km} \times 210 \mathrm{~km}$ & 142,884 \\
$300 \mathrm{~km} \times 300 \mathrm{~km}$ & 291,600 \\
$330 \mathrm{~km} \times 330 \mathrm{~km}$ & 352,836 \\
\hline
\end{tabular}

maximum precipitation only for the largest wind farms. Also, five of the six midlatitude cyclones realized greater maximum 30-minute accumulated precipitation with increasing wind farm size. The average $r^{2}$ value for midlatitude cyclones is 0.3713 (Table 3), while the average $r^{2}$ value for tropical cyclones is 0.0408 for the maximum 30-minute accumulated precipitation metric (Table 4). The average $p$ value for midlatitude cyclones is 0.1000 , while the average $p$ value for tropical cyclones is 0.7128 .

It is important to demonstrate the significance of the perturbation magnitudes found in this study. The perturbations found here exhibit magnitudes of nearly $8 \mathrm{hPa}$ for sea-level pressure and roughly $8 \mathrm{~m} / \mathrm{s}$ for surface wind speed. The typical variability of sea-level pressure and surface wind speed, either temporally or spatially, exhibits perhaps a $50 \mathrm{hPa}$ and $20 \mathrm{~m} / \mathrm{s}$ range, respectively. Thus, the perturbations modeled here show a substantial fraction (greater than $10 \%$ ) of the natural range of variability of these variables and can certainly be considered significant as they achieved these magnitudes over a 4-day simulation window.

3.5. Unrealistic Perturbations to Nonlocal cyclones. To determine whether the results above are due to the wind farm and not the unrealistic effects observed in the model, the 


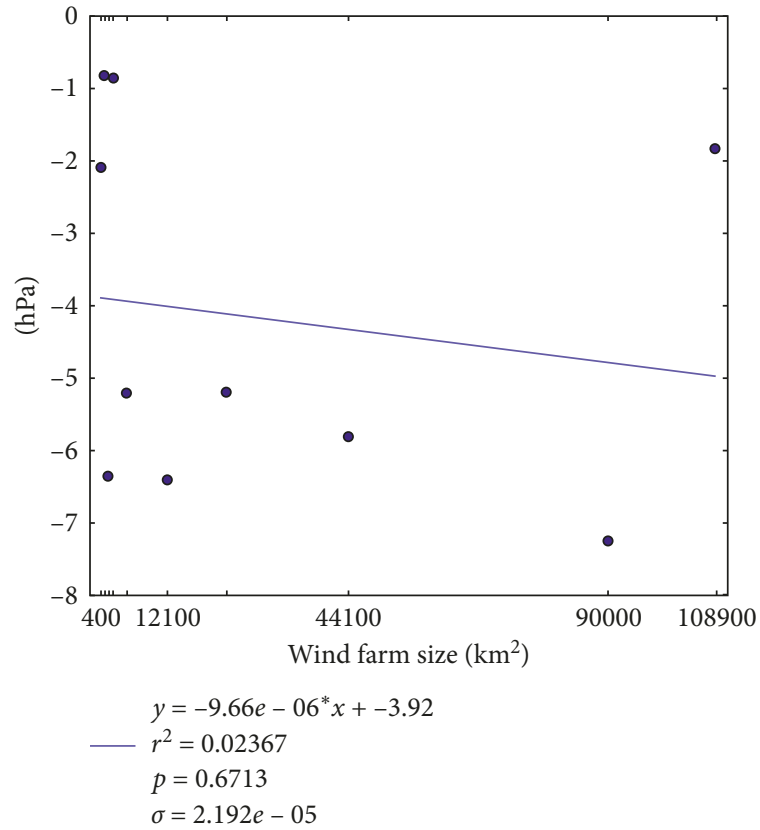

(a)

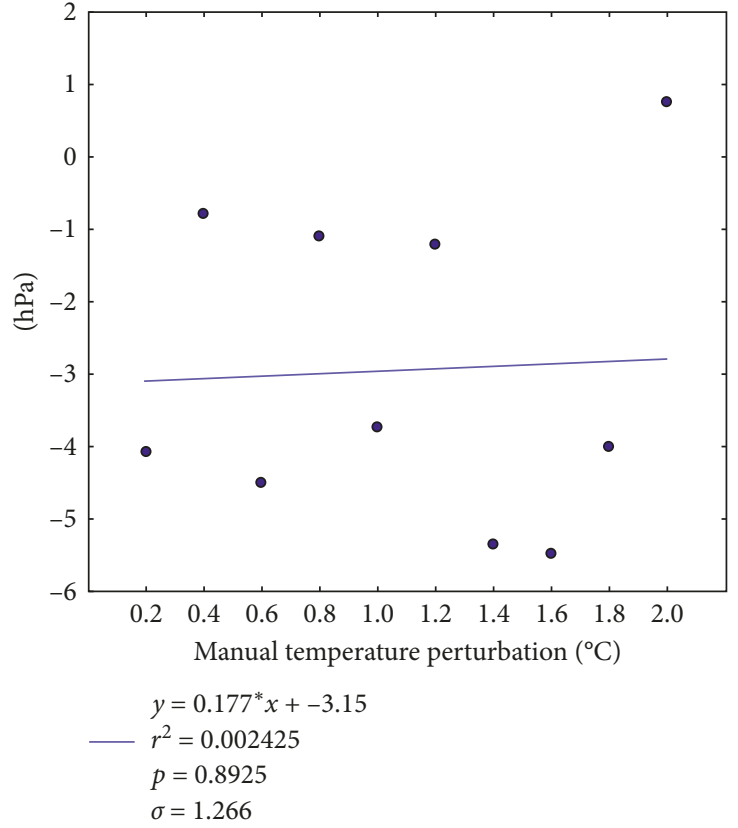

(b)

FIgURE 15: Largest perturbation of cyclone minimum sea-level pressure for the ten wind farm sizes (a) and unrealistic effects ensemble (b) for the 3 October 2013 tropical cyclone case.

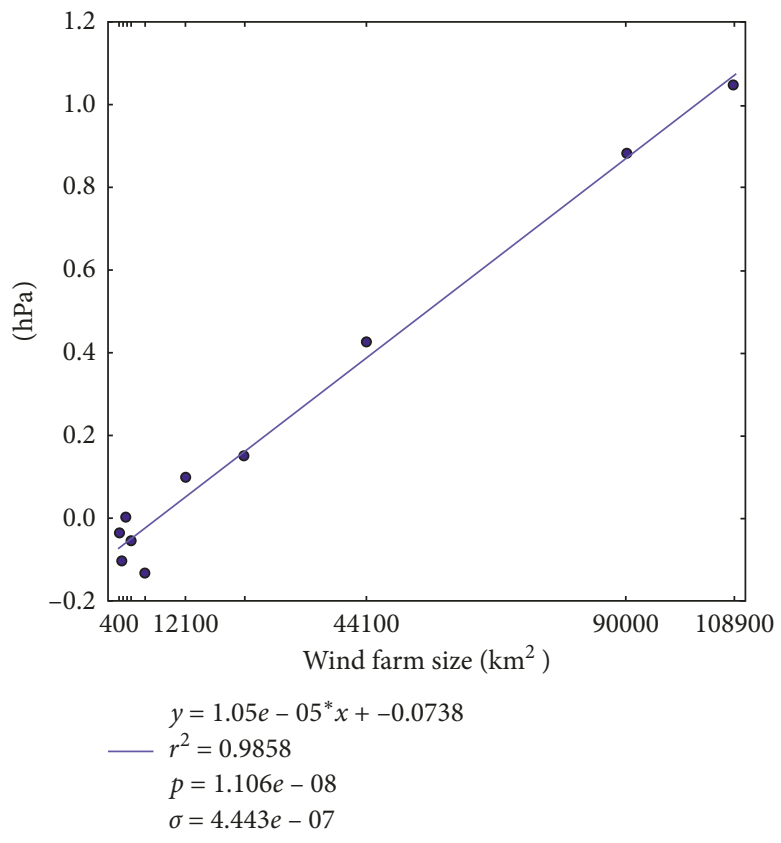

(a)

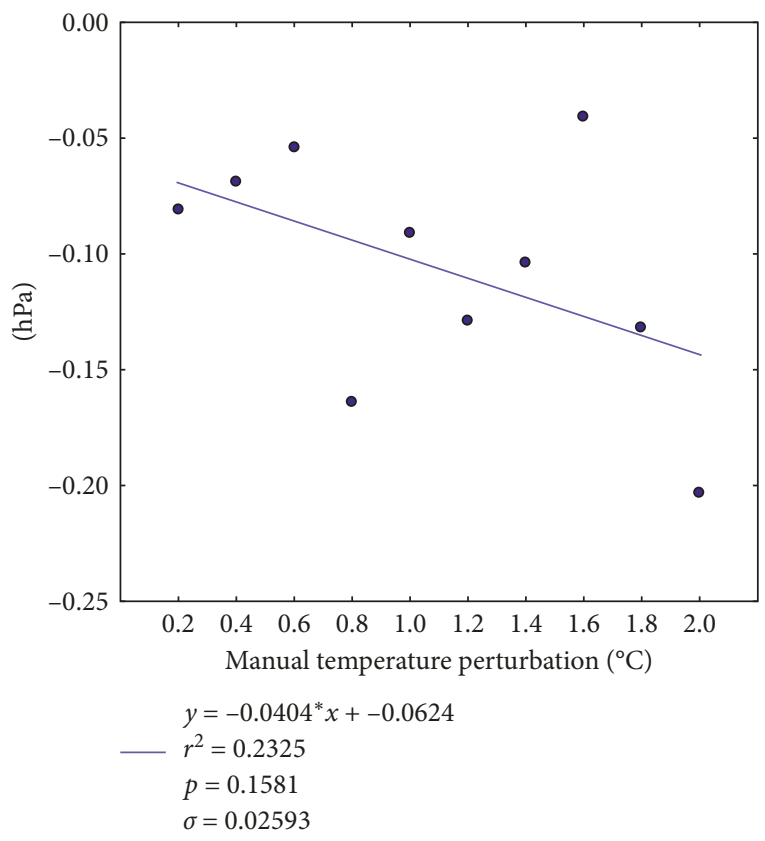

(b)

FIGURE 16: Largest perturbation of cyclone minimum sea-level pressure for the ten wind farm sizes (a) and unrealistic effects ensemble (b) for the 26 April 2014 midlatitude cyclone case.

same analysis as shown above is also applied to the ensemble of ten stratospheric temperature perturbations in the northeastern part of the domain. If the coefficient of determination $\left(r^{2}\right)$ is lower and $p$ value is higher for this ensemble when compared to the wind farm size ensemble results, we can determine that, in fact the results are due to the wind farm in the model. This is because the same relative unrealistic perturbations that occur throughout the domain with the wind farms included in the model, including the cyclones in question, are also observed when a perturbation is made to a grid cell in the stratosphere. This technique has been used in previous works such as [36]. 
TABle 3: Average coefficient of determination $\left(r^{2}\right)$, average $p$ value with the ratio of significant cases (95\% confidence), and largest perturbation to cyclone among midlatitude cyclones.

\begin{tabular}{lccc}
\hline Metric & Average $r^{2}$ & Average $p$ value (ratio of significance) & Largest perturbation \\
\hline Minimum mean sea-level pressure & 0.5900 & $0.1043(5 / 6)$ & $+1.047 \mathrm{hPa}$ \\
Maximum 10 m wind speed & 0.2984 & $0.2566(2 / 6)$ & $+4.1922 \mathrm{~m} / \mathrm{s}$ \\
Maximum 30-minute accumulated precipitation & 0.3713 & $0.1000(2 / 6)$ & $+15.3757 \mathrm{~mm}$ \\
Maximum 2 m temperature & 0.4898 & $0.1513(3 / 6)$ & $+0.520^{\circ} \mathrm{C}$ \\
Minimum 2 m temperature & 0.1533 & $0.4678(1 / 6)$ & $-0.273^{\circ} \mathrm{C}$ \\
Maximum 2 m potential temperature & 0.4328 & $0.2110(2 / 6)$ & $-0.139^{\circ} \mathrm{C}$ \\
Minimum 2 m potential temperature & 0.2172 & $0.2976(1 / 6)$ & $+1.082^{\circ} \mathrm{C}$ \\
Maximum boundary layer height & 0.2054 & $0.3974(1 / 6)$ & $+44.93 \mathrm{~m}$ \\
Maximum 2 m water vapor mixing ratio & 0.3372 & $0.2459(3 / 6)$ & $+0.5536 \mathrm{~g} / \mathrm{kg}$ \\
\hline
\end{tabular}

TABle 4: Average coefficient of determination $\left(r^{2}\right)$, average $p$ value with the ratio of significant cases (95\% confidence), and largest perturbation to cyclone among tropical cyclones.

\begin{tabular}{lccc}
\hline Metric & Average $r^{2}$ & Average $p$ value (ratio of significance) & Largest perturbation \\
\hline Minimum mean sea-level pressure & 0.0961 & $0.5229(0 / 4)$ & $-7.269 \mathrm{hPa}$ \\
Maximum 10 m wind speed & 0.0803 & $0.6077(0 / 4)$ & $+4.5865 \mathrm{~m} / \mathrm{s}$ \\
Maximum 30-minute accumulated precipitation & 0.0408 & $0.7128(0 / 4)$ & $+12.415 \mathrm{~mm}$ \\
Maximum 2 m temperature & 0.1953 & $0.3960(1 / 4)$ & $+0.6643^{\circ} \mathrm{C}$ \\
Minimum 2 m temperature & 0.1672 & $0.3175(0 / 4)$ & $+0.9814^{\circ} \mathrm{C}$ \\
Maximum 2 m potential temperature & 0.2299 & $0.2544(1 / 4)$ & $-0.698^{\circ} \mathrm{C}$ \\
Minimum 2 m potential temperature & 0.2312 & $0.3884(1 / 4)$ & $+1.225^{\circ} \mathrm{C}$ \\
Maximum boundary layer height & 0.1056 & $0.4518(0 / 4)$ & $-625.67 \mathrm{~m}$ \\
Maximum 2 m water vapor mixing ratio & 0.1794 & $0.3826(1 / 4)$ & $+0.2981 \mathrm{~g} / \mathrm{kg}$ \\
\hline
\end{tabular}

By comparison of the above results, Tables 5 and 6 display the difference in results between the wind farm size ensembles and stratospheric temperature perturbation ensembles. The greatest minimum sea-level pressure perturbations that occur with the ten potential temperature perturbations, the linear regression for these perturbations, and statistical values for all ten cases are included in Figures 15 and 16 for comparison to the earlier plots for the wind farm size ensembles.

For eight of the nine metrics regarding midlatitude cyclones, perturbations to the cyclone by the wind farms prove to be more significant, both in terms of the average coefficient of determination and the average $p$ value, than the unrealistic perturbations. The only metric that this does not apply to is the cyclone minimum $2 \mathrm{~m}$ temperature. Additionally, all eight of these metrics saw more significant $p$ values for the six midlatitude cyclone cases with the wind farm size ensemble. Observing the greatest perturbations to the nine metrics alone, the wind farm ensemble produced larger perturbations to all except for minimum sea-level pressure and minimum $2 \mathrm{~m}$ temperature.

Comparison of statistics between the two ensembles for tropical cyclones reveals that, for six of the nine metrics, perturbations to the cyclone by the wind farms prove to be more significant for both the average coefficient of determination and the average $p$ value. The three metrics that were not more significant for the wind farm size ensemble are minimum sea-level pressure, maximum 30-minute accumulated precipitation, and maximum boundary layer height. However, the only metric that had cases with more significant $p$ values is the maximum $2 \mathrm{~m}$ water vapor mixing ratio. There was no change in the number of significant $p$ values for six metrics, and the remaining two metrics of maximum 30-minute accumulated precipitation and maximum boundary layer height had more cases with significant $p$ values for the unrealistic perturbation ensemble versus the wind farm size ensemble. Examining the greatest perturbations shows larger perturbations from wind farms to all of the metrics except for maximum $10 \mathrm{~m}$ wind speed and maximum 30-minute accumulated precipitation.

Generally, higher coefficients of determination and lower $p$ values occur for the metric differences between the wind farm size ensemble and the control run than for the metric differences between the stratospheric temperature perturbations ensemble and the control run. Therefore, the observed perturbations to the cyclones are more dependent on the size of the wind farm than the magnitude of temperature perturbation made in the stratosphere far away from the cyclone. The metrics where we cannot make this claim are the minimum $2 \mathrm{~m}$ temperature for midlatitude cyclones and minimum sea-level pressure, maximum 30minute accumulated precipitation, and maximum boundary layer height for tropical cyclones.

\section{Summary and Conclusions}

With the increase in the number of and spatial extent of wind farms in the United States, an important potential consequence is an inadvertent change in weather. The main goal of this study is to determine whether wind farminduced perturbations can evolve over periods of days, and over areas of thousands of square kilometers, to modify specific atmospheric features that have large impacts on society and the environment. This research used an 
TABLE 5: Difference between the wind farm ensemble and stratospheric temperature perturbation ensemble in the average coefficient of determination $\left(r^{2}\right)$, average $p$ value, and the ratio of significant cases for perturbations to midlatitude cyclones.

\begin{tabular}{lcc}
\hline Metric & Average $r^{2}$ & Average $p$ value (ratio of significance) \\
\hline Minimum mean sea-level pressure & +0.4758 & $-0.2797(+5 / 6)$ \\
Maximum 10 m wind speed & +0.1385 & $-0.2593(+1 / 6)$ \\
Maximum 30-minute accumulated precipitation & +0.2502 & $-0.2995(+2 / 6)$ \\
Maximum 2 m temperature & +0.3932 & $-0.2858(+3 / 6)$ \\
Minimum 2 m temperature & -0.0547 & $+0.1472(0 / 6)$ \\
Maximum 2 m potential temperature & +0.3641 & $-0.2758(+2 / 6)$ \\
Minimum 2 m potential temperature & +0.0730 & $-0.1464(+1 / 6)$ \\
Maximum boundary layer height & +0.1489 & $-0.2304(+1 / 6)$ \\
Maximum 2 m water vapor mixing ratio & +0.2140 & $-0.2205(+2 / 6)$ \\
\hline
\end{tabular}

TABLE 6: Difference between the wind farm ensemble and stratospheric temperature perturbation ensemble in the average coefficient of determination $\left(r^{2}\right)$, average $p$ value, and the ratio of significant cases for perturbations to tropical cyclones.

\begin{tabular}{lcc}
\hline Metric & Average $r^{2}$ & Average $p$ value (ratio of significance) \\
\hline Minimum mean sea-level pressure & -0.0170 & $+0.0545(0 / 4)$ \\
Maximum 10 m wind speed & +0.0701 & $-0.1867(0 / 4)$ \\
Maximum 30-minute accumulated precipitation & -0.0731 & $+0.1809(-1 / 4)$ \\
Maximum 2 m temperature & +0.0539 & $-0.1004(0 / 4)$ \\
Minimum 2 m temperature & +0.0715 & $-0.1750(0 / 4)$ \\
Maximum 2 m potential temperature & +0.0199 & $-0.1099(0 / 4)$ \\
Minimum 2 m potential temperature & +0.017 & $-0.0044(0 / 4)$ \\
Maximum boundary layer height & -0.1276 & $+0.0057(-1 / 4)$ \\
Maximum 2 m water vapor mixing ratio & +0.0696 & $-0.0963(+1 / 4)$ \\
\hline
\end{tabular}

ensemble approach with the WRF mesoscale model and the Fitch wind farm parameterization to quantify the sensitivity of meteorological variables to the presence of wind farms.

The results show that wind farms located in the Central United States were in fact capable of significantly altering midlatitude cyclones, but not tropical cyclones, and can cause large perturbations up to hundreds of kilometers away, including perturbations to the minimum cyclone pressure of $1 \mathrm{hPa}$, maximum $2 \mathrm{~m}$ temperature of $0.5^{\circ} \mathrm{C}$, maximum 30 minute accumulated precipitation of $15 \mathrm{~mm}$, and maximum $2 \mathrm{~m}$ wind speed of $4 \mathrm{~m} / \mathrm{s}$. Wind farms were shown to both increase and decrease the strength of midlatitude cyclones, and the outcome is likely due to the positioning of the wind farm with respect to the location of cyclogenesis. The majority of midlatitude cyclone cases show that wind farms placed nearer to or more upstream of the area of cyclogenesis lead to negative pressure perturbations and positive wind speed perturbations. Wind farms placed downstream tend to result in positive pressure perturbations. This implies that wind farms upstream of the region of cyclogenesis increase the strength of the cyclone, while wind farms downstream of cyclogenesis decrease the cyclone strength. Comparing the results of midlatitude cyclone perturbations by wind farms to the perturbations by unrealistic effects, it can be seen that the wind farm-induced perturbations are substantially more statistically significant than the unrealistic effects in general. This gives us confidence that results presented are truly due to the wind farm and not a result of the unrealistic noise.

As this work answers the question of whether wind farms can modify synoptic scales at timescales of days, it is impossible to conclude that such a systematic evolution is true more generally given the small sample size used here. Future work planned given the motivation gained in this study will aim to discover whether such systematic changes are robust.

The average coefficient of determination and the average $p$ value among midlatitude cyclones were more significant for all metrics except for cyclone minimum $2 \mathrm{~m}$ temperature. Additionally, those metrics saw more significant $p$ values when comparing wind farm size ensemble runs versus the unrealistic perturbation runs. The average coefficient of determination and the average $p$ value among tropical cyclones were more significant for six of nine metrics, however by a relatively small amount. Also, the only metric that saw significant $p$ values was the maximum $2 \mathrm{~m}$ water vapor mixing ratio.

When modeling nonlocal wind farm impacts on tropical cyclones, confidence in perturbation results is low. Tropical cyclones inherently have more moisture and convection than midlatitude cyclones. With it being shown that unrealistic effects were occurring in the model due to the rapid growth of noise in the moist physics, the ensemble of unrealistic perturbations showed that these wind farm modifications were not more statistically significant than the unrealistic perturbations to the tropical cyclone. Therefore, the signal obtained from tropical cyclone modifications primarily lies within the noise created by the model. More generally, the primary mechanism driving nonlocal inadvertent weather modification demonstrated here involves an initial local modification, followed by subsequent growth and evolution of those perturbations downstream similar to the processes examined in prior sensitivity studies of cyclones. This further explains the significance behind the relationship between midlatitude cyclones, which evolved near the wind farm locations, and the lack of such a relationship with regard to tropical cyclones, which did not. 
It has been determined here that wind farms can significantly modify nonlocal midlatitude cyclones. In turn, this motivates future studies to better define the degree of nonlocal inadvertent modification of cyclones and whether these are systematic changes, and this is a planned next step in this research. The approach taken here can also be applied to other weather features, such as fronts or convective initiation, to obtain a greater understanding of how wind farms are altering the broader atmospheric state. This understanding is very applicable more broadly to forecasting such events, as large changes due to wind farms would suggest that forecast skill can depend on simulating the effects of wind farms by numerical weather prediction models. Additionally, the roles of different wind farm/turbine configurations in inadvertent weather modification are another avenue of future research. The size of future wind farms is relatively unknown, though, as it is dependent on public opinion of wind energy and the willingness of property owners to lease their land to utility companies for the placement of wind turbines. Moreover, our results may not apply generally to a range of coarser turbine spacings, which should be studied in future research. Finally, adjoint or ensemble sensitivity techniques can be utilized to better estimate the largest perturbations to high-impact weather features by first locating regions of high sensitivity and then placing an ensemble of wind farm sizes in that location. This approach would effectively determine "worst-case scenarios" for how wind farms might impact not only weather features but society and the environment as well, toward the responsible management of these effects in the future.

\section{Data Availability}

The data used to support the findings of this study are available from the corresponding author upon request.

\section{Disclosure}

This paper was presented at the Workshop on Sensitivity Analysis and Data Assimilation in Meteorology and Oceanography (2015) and the Conference on Planned and Inadvertent Weather Modification (2015). Matthew J. Lauridsen is currently at Fleet Numerical Meteorology and Oceanography Center, Monterey, CA.

\section{Conflicts of Interest}

The authors declare that they have no conflicts of interest.

\section{References}

[1] L. Zhou, Y. Tian, S. Baidya Roy, C. Thorncroft, L. F. Bosart, and $\mathrm{Y} . \mathrm{Hu}$, "Impacts of wind farms on land surface temperature," Nature Climate Change, vol. 2, no. 7, pp. 539-543, 2012.

[2] L. Zhou, Y. Tian, H. Chen, Y. Dai, and R. A. Harris, "Effects of topography on assessing wind farm impacts using MODIS data," Earth Interactions, vol. 17, no. 13, pp. 1-18, 2013.
[3] M. B. Christiansen and C. B. Hasager, "Wake effects of large offshore wind farms identified from satellite SAR," Remote Sensing of Environment, vol. 98, no. 2-3, pp. 251-268, 2005.

[4] S. Baidya Roy, S. W. Pacala, and R. L. Walko, "Can large wind farms affect local meteorology?," Journal of Geophysical Research, vol. 109, p. 6, 2004.

[5] D. B. Barrie and D. B. Kirk-Davidoff, "Weather response to a large wind turbine array," Atmospheric Chemistry and Physics, vol. 10, no. 2, pp. 769-775, 2010.

[6] B. H. Fiedler and M. S. Bukovsky, "The effect of a giant wind farm on precipitation in a regional climate model," Environmental Research Letters, vol. 6, article 045101, 2011.

[7] A. C. Fitch, J. B. Olson, J. K. Lundquist et al., "Local and mesoscale impacts of wind farms as parameterized in a mesoscale NWP model," Monthly Weather Review, vol. 140, no. 9, pp. 3017-3038, 2012.

[8] D. W. Keith, J. F. Decarolis, D. C. Denkenberger et al., "The influence of large-scale wind power on global climate," Proceedings of the National Academy of Sciences of the United States of America, vol. 101, no. 46, pp. 16115-16120, 2004.

[9] D. B. Kirk-Davidoff and D. W. Keith, "On the climate impact of surface roughness anomalies," Journal of the Atmospheric Sciences, vol. 65, no. 7, pp. 2215-2234, 2008.

[10] C. Wang and R. G. Prinn, "Potential climatic impacts and reliability of very large-scale wind farms," Atmospheric Chemistry and Physics, vol. 10, no. 4, pp. 2053-2061, 2010.

[11] S Baidya Roy, "Simulating impacts of wind farms on local hydrometeorology," Journal of Wind Engineering and Industrial Aerodynamic, vol. 99, no. 4, pp. 491-498, 2011.

[12] A. C. Fitch, J. B. Olson, and J. K. Lundquist, "Parameterization of wind farms in climate models," Journal of Climate, vol. 26, no. 17, pp. 6439-6458, 2013.

[13] E. N. Lorenz, "Deterministic nonperiodic flow," Journal of the Atmospheric Sciences, vol. 20, no. 2, pp. 130-141, 1963.

[14] F. Zhang, C. Snyder, and R. Rotunno, "Effects of moist convection on mesoscale predictability," Journal of the Atmospheric Sciences, vol. 60, no. 9, pp. 1173-1185, 2003.

[15] M. S. Peng and C. A. Reynolds, "Sensitivity of tropical cyclone forecasts as revealed by singular vectors," Journal of the Atmospheric Sciences, vol. 63, no. 10, pp. 2508-2528, 2006.

[16] C. A. Reynolds, M. S. Peng, and J.-H. Chen, "Recurving tropical cyclones: singular vector sensitivity and downstream impacts," Monthly Weather Review, vol. 137, no. 4, pp. 1320-1337, 2009.

[17] B. C. Ancell and C. F. Mass, "Structure, growth rates, and tangent linear accuracy of adjoint sensitivities with respect to horizontal and vertical resolution," Monthly Weather Review, vol. 134, no. 10, pp. 2971-2988, 2006.

[18] R. H. Langland, R. L. Elsberry, and R. M. Errico, "Evaluation of physical processes in an idealized extratropical cyclone using adjoint sensitivity," Quarterly Journal of the Royal Meteorological Society, vol. 121, no. 526, pp. 1349-1386, 1995.

[19] T. Vukicevic and K. Raeder, "Use of an adjoint model for finding triggers for Alpine lee cyclogenesis," Monthly Weather Review, vol. 123, no. 3, pp. 800-816, 1995.

[20] X. Zou, Y.-H. Kuo, and S. Low-Nam, "Medium-range prediction of an extratropical oceanic cyclone: impact of initial state," Monthly Weather Review, vol. 126, no. 11, pp. 27372763, 1998.

[21] American Meteorological Society Council, "Inadvertent weather modification: an information statement of the American Meteorological Society, AMS," 2010, https://www.ametsoc. org/ams/index.cfm/about-ams/ams-statements/statementsof-the-ams-in-force/inadvertent-weather-modification/. 
[22] R. M. Errico, "What is an adjoint model?," Bulletin of the American Meteorological Society, vol. 78, no. 11, pp. 2577-2591, 1997.

[23] W. C. Skamarock and Coauthors, "A description of the advanced research WRF version 3,” NCAR Tech. Note NCAR/ TN-475+STR, 2008.

[24] G. Thompson, P. R. Field, R. M. Rasmussen, and W. D. Hall, "Explicit forecasts of winter precipitation using an improved bulk microphysics scheme. Part II: implementation of a new snow parameterization," Monthly Weather Review, vol. 136, no. 12 , pp. 5095-5115, 2008.

[25] E. J. Mlawer, S. J. Taubman, P. D. Brown, M. J. Iacono, and S. A. Clough, "Radiative transfer for inhomogeneous atmospheres: RRTM, a validated correlated-k model for the longwave," Journal of Geophysical Research: Atmospheres, vol. 102, no. D14, pp. 16663-16682, 1997.

[26] J. Dudhia, "Numerical study of convection observed during the Winter Monsoon Experiment using a mesoscale twodimensional model," Journal of the Atmospheric Sciences, vol. 46, no. 20, pp. 3077-3107, 1989.

[27] Z. Janjic, "The step-mountain eta coordinate model: further developments of the convection, viscous sublayer, and turbulence closure schemes," Monthly Weather Review, vol. 122, no. 5, pp. 927-945, 1994.

[28] F. Chen and J. Dudhia, "Coupling an advanced land surface-hydrology model with the Penn State-NCAR MM5 modeling system. Part II: preliminary model validation," Monthly Weather Review, vol. 129, no. 4, pp. 587-604, 2001.

[29] M. Nakanishi and H. Niino, "An improved Mellor-Yamada level-3 model: its numerical stability and application to a regional prediction of advection fog," Boundary-Layer Meteor, vol. 119, no. 2, pp. 397-407, 2006.

[30] M. Nakanishi and H. Niino, "Development of an improved turbulence closure model for the atmospheric boundary layer," Journal of the Meteorological Society of Japan, vol. 87, no. 5, pp. 895-912, 2009.

[31] J. S. Kain, "The Kain-Fritsch convective parameterization: an update," Journal of Applied Meteorology, vol. 43, no. 1, pp. 170-181, 2004.

[32] F. Zhang, A. M. Odins, and J. W. Neilsen-Gammon, "Mesoscale predictability of an extreme warm-season precipitation event," Weather and Forecasting, vol. 21, no. 2, pp. 149-166, 2006.

[33] J. P. Hacker, "Spatial and temporal scales of boundary layer wind predictability in response to small-amplitude land surface uncertainty," Journal of the Atmospheric Sciences, vol. 67, no. 1, pp. 217-233, 2010.

[34] C. Hohenegger and C. Schar, "Predictability and error growth dynamics in cloud-resolving models," Journal of the Atmospheric Sciences, vol. 64, no. 12, pp. 4467-4478, 2007.

[35] D. Hodyss and S. Majumdar, "The contamination of 'data impact' in global models by rapidly growing mesoscale instabilities," Quarterly Journal of the Royal Meteorological Society, vol. 133, pp. 1865-1875, 2007.

[36] B. C. Ancell, A. Bogusz, M. J. Lauridsen, and C. J. Nauert, "Seeding chaos: the dire consequences of numerical noise in NWP perturbation experiments," Bulletin of the American Meteorological Society, vol. 99, no. 3, pp. 615-628, 2018.

[37] M. J. Lauridsen, "Nonlocal inadvertent weather modification associated with wind farms in the Central United States," Masters Thesis, Texas Tech University, 2015.

[38] R. Lorenz, A. J. Pitman, and S. A. Sisson, "Does Amazonian deforestation cause global effects; can we be sure?," Journal of Geophysical Research: Atmospheres, vol. 121, no. 10, pp. 55675584, 2016. 

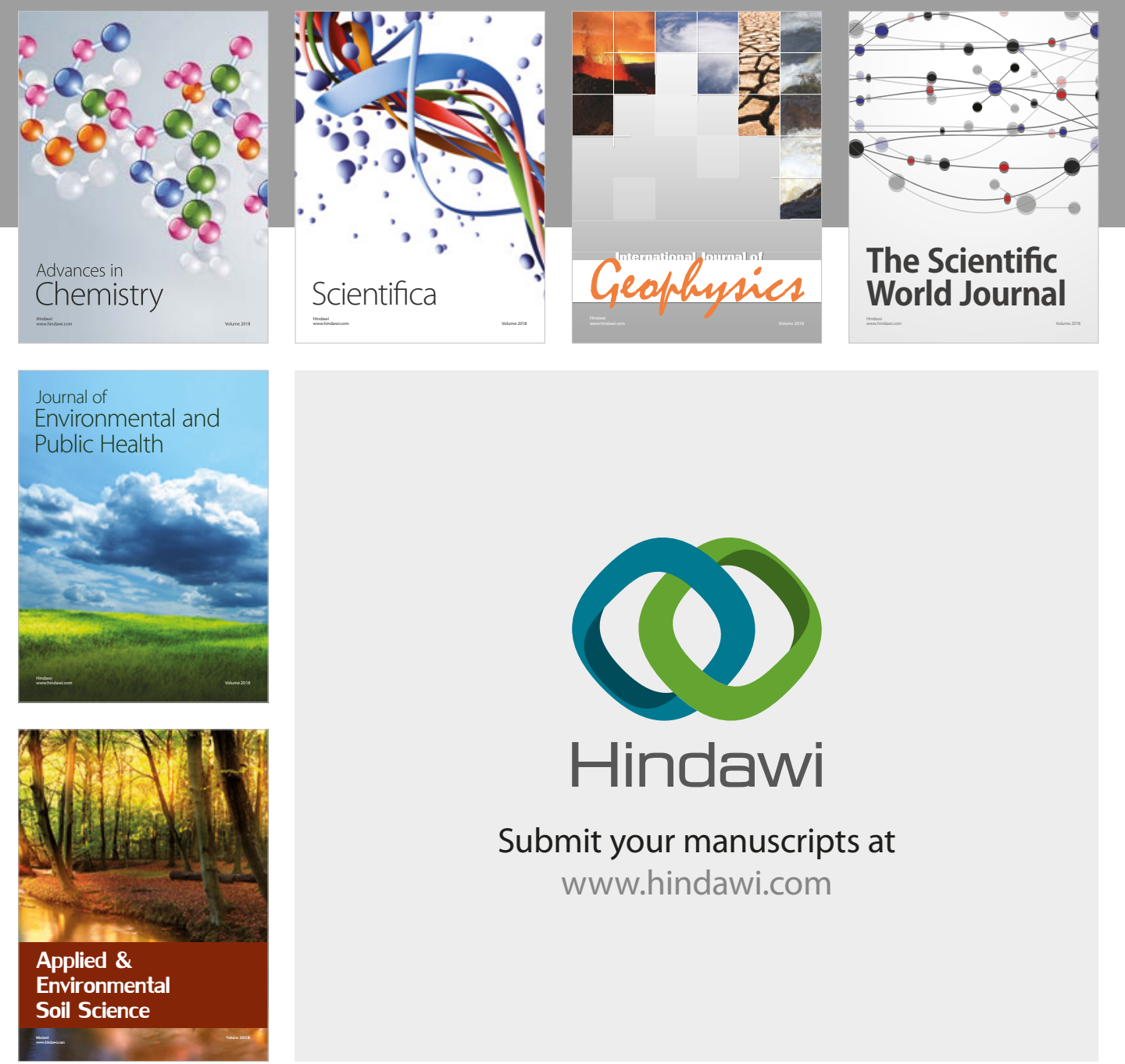

The Scientific

\section{World Journal}
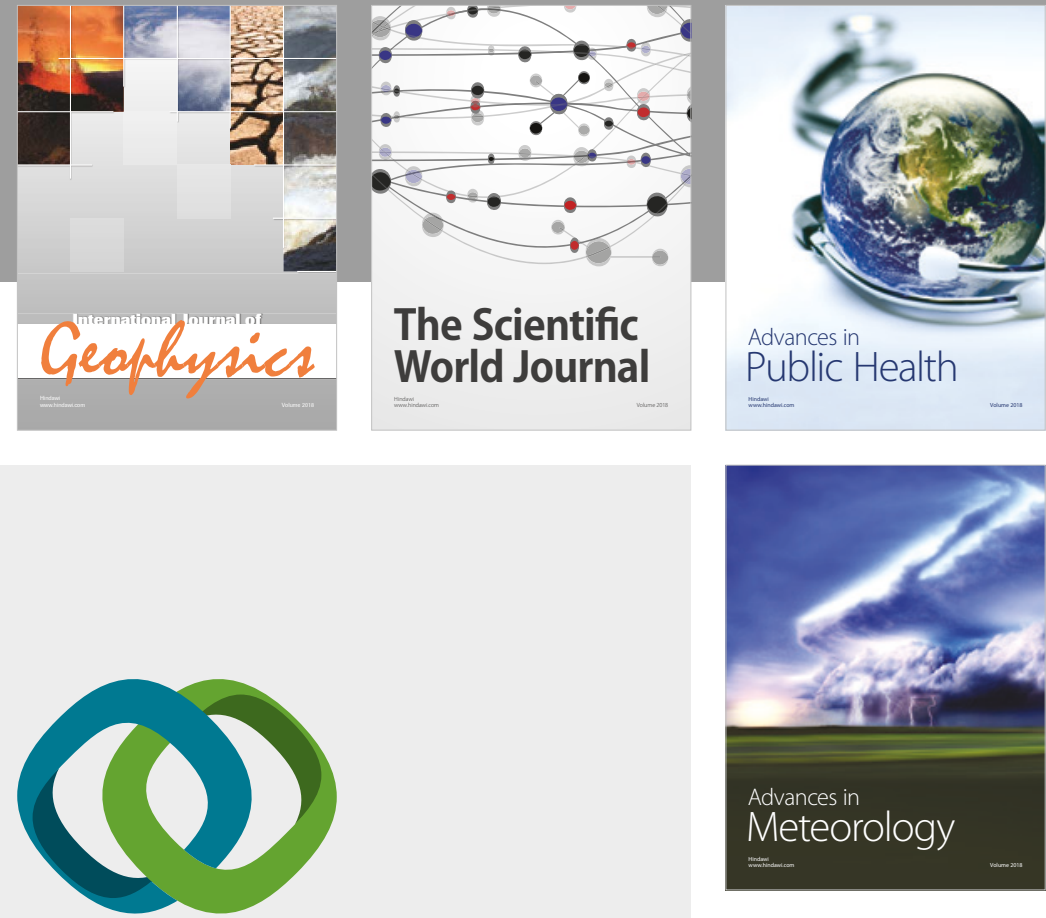

Advan

Public Health

\section{Hindawi}

Submit your manuscripts at

www.hindawi.com
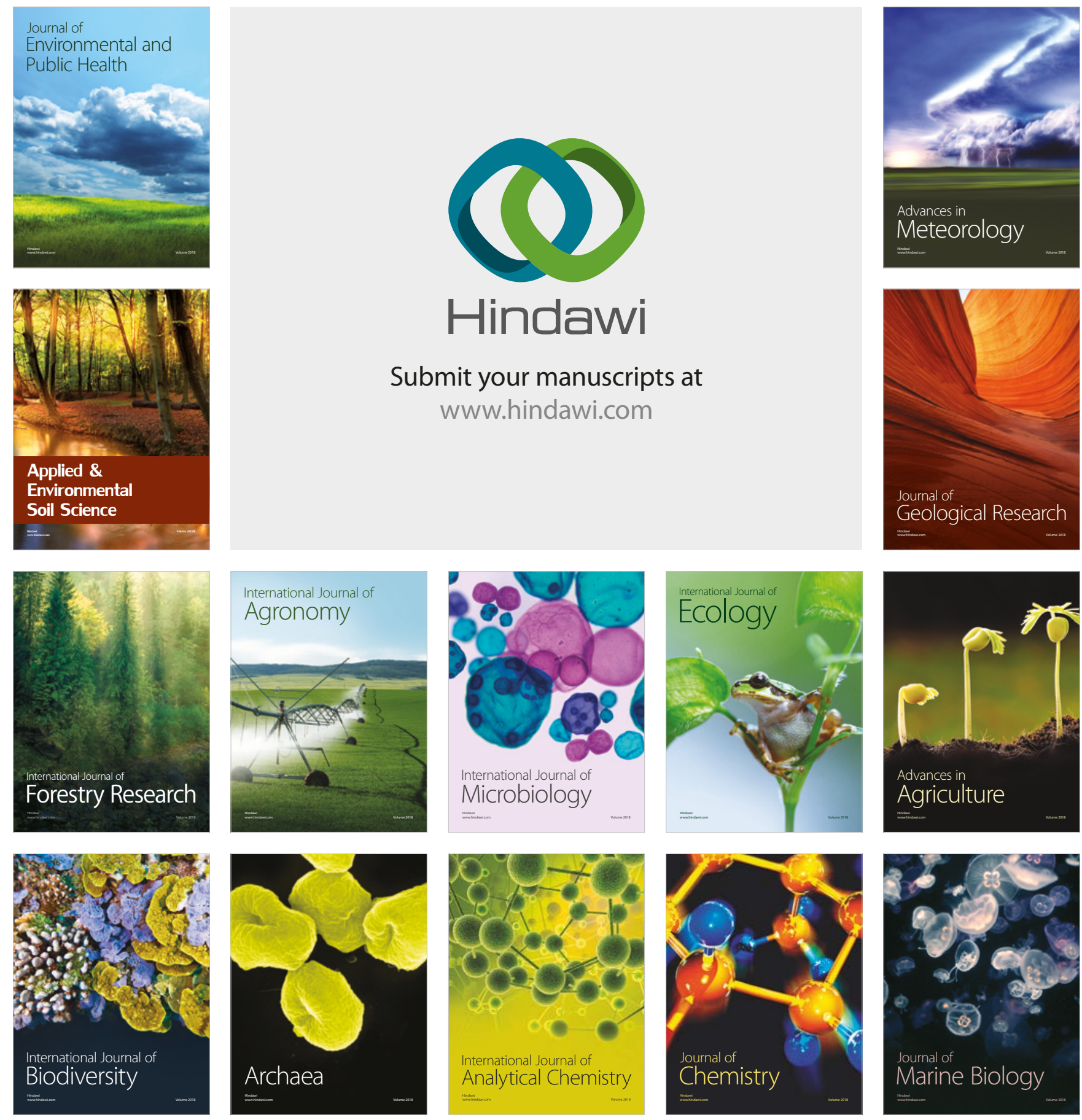